\title{
Symbiotic microbes affect the expression of male reproductive genes in Glossina m. morsitans
}

Francesca Scolari ${ }^{1 \dagger}$, Geoffrey Michael Attardo ${ }^{2,3 \dagger}$, Emre Aksoy², Brian Weiss ${ }^{2}$, Grazia Savini ${ }^{1}$, Peter Takac ${ }^{4}$, Adly Abd-Alla ${ }^{5}$, Andrew Gordon Parker ${ }^{5}$, Serap Aksoy ${ }^{2}$ and Anna Rodolfa Malacrida ${ }^{1^{*}}$

\begin{abstract}
Background: Tsetse flies (Diptera, Glossinidae) display unique reproductive biology traits. Females reproduce through adenotrophic viviparity, nourishing the growing larva into their modified uterus until parturition. Males transfer their sperm and seminal fluid, produced by both testes and male accessory glands, in a spermatophore capsule transiently formed within the female reproductive tract upon mating. Both sexes are obligate blood feeders and have evolved tight relationships with endosymbionts, already shown to provide essential nutrients lacking in their diet. However, the partnership between tsetse and its symbionts has so far been investigated, at the molecular, genomic and metabolomics level, only in females, whereas the roles of microbiota in male reproduction are still unexplored.

Results: Here we begin unravelling the impact of microbiota on Glossina m. morsitans (G. morsitans) male reproductive biology by generating transcriptomes from the reproductive tissues of males deprived of their endosymbionts (aposymbiotic) via maternal antibiotic treatment and dietary supplementation. We then compared the transcriptional profiles of genes expressed in the male reproductive tract of normal and these aposymbiotic flies. We showed that microbiota removal impacts several male reproductive genes by depressing the activity of genes in the male accessory glands (MAGs), including sequences encoding seminal fluid proteins, and increasing expression of genes in the testes. In the MAGs, in particular, the expression of genes related to mating, immunity and seminal fluid components' synthesis is reduced. In the testes, the absence of symbionts activates genes involved in the metabolic apparatus at the basis of male reproduction, including sperm production, motility and function.
\end{abstract}

Conclusions: Our findings mirrored the complementary roles male accessory glands and testes play in supporting male reproduction and open new avenues for disentangling the interplay between male insects and endosymbionts. From an applied perspective, unravelling the metabolic and functional relationships between tsetse symbionts and male reproductive physiology will provide fundamental information useful to understanding the biology underlying improved male reproductive success in tsetse. This information is of particular importance in the context of tsetse population control via Sterile Insect Technique (SIT) and its impact on trypanosomiasis transmission.

Keywords: Tsetse, Endosymbionts, Aposymbiotic, Testes, MAGs, Ejaculate, Spermatophore

\footnotetext{
* Correspondence: malacrid@unipv.it

${ }^{\dagger}$ Francesca Scolari and Geoffrey Michael Attardo contributed equally to this work.

'Department of Biology and Biotechnology, University of Pavia, 27100 Pavia, Italy

Full list of author information is available at the end of the article
}

c) International Atomic Energy Agency; licensee BioMed Central Ltd. 2018 This is an open access article distributed under the terms of the Creative Commons Attribution IGO License (https://creativecommons.org/licenses/by/3.0/igo/) which permits unrestricted use, distribution, and reproduction in any medium, provided appropriate credit to the original author(s) and the source is given. 


\section{Background}

Among Diptera, tsetse flies (Glossina spp.) display unique reproductive biology traits, including adenotrophic viviparity [1] and ejaculate transfer through a spermatophore capsule transiently formed within the female uterus [2,3]. In addition, both sexes in tsetse are obligate blood feeders, and, as such, have evolved relationships with obligate symbionts providing essential nutrients lacking in their vertebrate blood diet [4-6]. These symbionts influence multiple aspects of tsetse female physiology, including nutrition, fecundity and immunity. To date, three main endosymbionts have been described in tsetse with one, Wigglesworthia glossinidia, being an obligate association found in all tsetse examined. Wigglesworthia glossinidia provides key metabolites, including vitamins, known to be present at low titers in the vertebrate blood [4]. Absence of Wigglesworthia results in larval abortion due in part to depletion of components of the $\mathrm{B}$ vitamin complex (specifically vitamins B1, B2 and B6), necessary co-factors for key metabolic pathways in G. morsitans [7]. Additional genetic/physiological adaptations include reliance on chaperonins for protein synthesis in Wigglesworthia, and enrichment of nutrient transport mechanisms by Glossina's bacteriocytes. These findings further support the direct and indirect obligate interdependencies between tsetse and Wigglesworthia. This long-term co-evolutionary association has led to a multitude of dynamic molecular and biochemical interactions that ensures the optimal fitness of the partnership [4]. It remains to be determined whether the absence of Wigglesworthia has adverse nutritional effects on male biology that impact reproductive success. The commensal endosymbiont Sodalis glossinidius is widely distributed in various tissues, including the testes. While both Sodalis and Wigglesworthia undergo maternal transmission to the developing larva via the milk secretions of the mother [8], Sodalis can also be paternally transmitted through the ejaculate [9]. However, the role of Sodalis in tsetse's male reproductive physiology remains unknown. This aspect is of particular interest in tsetse as recent works begin to unravel the role of facultative endosymbionts on male reproductive fitness in other insects [10]. As occurs in many other insect taxa, the gonads of the tsetse species G. morsitans also harbour the transovarially-transmitted Wolbachia pipientis, which can manipulate the reproductive biology of their hosts through multiple mechanisms, including cytoplasmic incompatibility (CI), which was noted in tsetse [11, 12]. Wolbachia prevalence in wild G. morsitans populations ranges from 9.5 to $100 \%$ [13] and such infection dynamics could be a result of the extensive genetic structuring estimated for tsetse populations [14, 15]. Moreover, three Wolbachia chromosome insertions have been identified in G. m. morsitans nuclear genome, with the two largest fragments carrying several putatively functional coding sequences [16]. These include genes encoding proteins with ankyrin repeat domains, considered to play a relevant role in Wolbachia-host interactions, despite their involvement in CI has not been confirmed yet [17-19]. Although the molecular basis of CI remains unknown, in Drosophila, Wolbachia has been shown to affect gene transcription in larval testes [20] and impact seminal fluid protein expression [21]. Wolbachia also affect the expression of immunity genes in a parasitoid wasp [22] and in mosquitoes [23]. It accomplishes this by influencing levels of host microRNAs (miRNA) that target specific host proteins as well as producing small RNAs that regulate mosquito gene expression $[24,25]$. However, the potential effects of this bacterium on ejaculate composition and function, and thus on male reproductive success, remain unknown. This knowledge gap in tsetse is exacerbated by the fact that the symbiotic dialogue supporting the fitness of the partnership between tsetse and its symbionts has so far been investigated, at the molecular, genomic and metabolomics level, only in females.

Given the increasingly growing data supporting the role of the microbiota in the modification of host mating signals directly affecting mate choice (see [26] for a review), and our recent data showing the impact of Wigglesworthia on carbohydrate and amino acid metabolism [4], we hypothesize the presence of a direct effect of microbiota on G. morsitans male reproductive biology. This idea is further supported by data obtained from other insect species, which suggest that male macronutrient intake, carbohydrates in particular, influences sperm number [27]. To test this hypothesis, here we have taken advantage of the ability to generate fertile tsetse laboratory lines lacking endosymbionts (aposymbiotic), developed through the treatment of female flies with antibiotics and dietary yeast extract supplementation, which rescues Wigglesworthia-induced sterility [12, 28]. These flies produce offspring lacking all symbiotic bacteria. We compared the transcriptional profiles of genes expressed in the male reproductive tract of normal and aposymbiotic flies. Our previous transcriptomic and proteomic analyses revealed the protein composition of the spermatophore in G. morsitans and determined the tissues of origin of these proteins within the reproductive tract (testes and/or male accessory glands (MAGs)) of males with full microbiota [3]. This work suggested that these two reproductive tissues both contribute to the formation of spermatophore components, with MAGs producing highly abundant proteins of unknown function and the testes contributing a more diverse array of less abundant proteins. Considering the tight metabolic relationships established between tsetse and its endosymbionts, it is likely that this obligate symbiosis affects host physiological pathways important for male reproductive functions. Aposymbiotic males remain 
fertile and produce progeny [12], however the molecular impact of male aposymbiosis is unknown. Here we show that the absence of microbiota impacts a number of male reproductive genes by depressing gene activity in the MAGs, including sequences encoding seminal fluid proteins, and by increasing genes expression in the testes. Interestingly, our findings mirror the complementary roles MAGs and testes play in supporting male reproduction and open new avenues for disentangling the interplay between male insects and endosymbionts.

\section{Results}

\section{Symbiont presence affects the expression of male reproductive genes}

To determine whether endosymbionts play a role on the expression of male reproductive genes in G. morsitans, aposymbiotic $\left(\mathrm{Gmm}^{\mathrm{Apo}}\right)$ individuals were generated as progeny of tetracycline-treated females. Their symbiont-free status was verified by PCR assays for the presence of the three endosymbionts of tsetse, i.e. Wigglesworthia, Sodalis and Wolbachia, using bacterium-specific primers [12]. The PCRs clearly showed the absence of all three endosymbionts from both male and female flies (Additional file 1). These $\mathrm{Gmm}^{\text {Apo }}$ males, as well as males with a full symbiont complement $\left(\mathrm{Gmm}^{\mathrm{WT}}\right.$, control), were then used for the generation of transcriptomes from reproductive tissues (including the accessory glands, testes and ejaculatory duct), in three biological replicates [29]. About 19 million high-quality reads were obtained from each replicate. Reads were mapped to the predicted transcripts dataset from the G. morsitans genome as previously described [3]. A total of 8353 transcripts were identified as being significantly expressed in the reproductive tract. Principal Component Analysis (PCA) performed to compare global gene expression between the libraries demonstrated that the expression was structured according to the presence/absence of symbionts (Additional file 2). Indeed, the $\mathrm{Gmm}^{\mathrm{Apo}}$ and the $\mathrm{Gmm}^{\mathrm{WT}}$ libraries separated along the first principal component, which explained 59\% of the variance. The transcripts were then categorized as significantly up- or down-regulated in $\mathrm{Gmm}^{\text {Apo }}$ versus $\mathrm{Gmm}^{\text {WT }}$ reproductive tissues by edge $R$ analysis $(P<0.05$ and false discovery rate (FDR) score $<0.01$ ). A total of 135 genes were identified as differentially expressed. Of those, 55 were down-regulated and 80 were up-regulated in the $\mathrm{Gmm}^{\text {Apo }}$ male tissues (Fig. 1, Additional file 3). Both up- and down-regulated gene datasets displayed similar distributions across the functional classes of the Gene Ontology (GO) categories (Additional files 4, 5 and 6). In the Biological Process GO, the most represented classes were cellular, metabolic and single-organism processes, while in the Molecular Function catalytic activity and binding were the predominant GO classes. Interestingly, about $50 \%$ of the up-regulated genes could be related to the membrane term (Cellular
Component). It is noteworthy that a different trend of transcriptional variation, in relation to the controls, has been observed between up- and down-regulated genes. Indeed, as shown in Fig. 2, up-regulated genes tended to cluster within a relatively narrow expression variation interval (log2 ranging from about 5 to 12), whereas the variation interval of down-regulated genes was broader with some very highly expressed genes being represented $(\log 2$ ranging from about 4 to 20 ).

The availability of libraries previously generated from $\mathrm{Gmm}^{\mathrm{WT}}$ MAG and testes allowed us to assess the preferential transcription of the genes that were up- and down-regulated in $\mathrm{Gmm}^{\text {Apo }}$ males in these two male tissues [3] (Additional file 3). Out of the 55 down-regulated genes, $22(40 \%)$ displayed a biased expression in the MAGs (Table 1), while only five were associated with the testes (Table 2). The remaining 28 genes (51\%) displayed an unbiased transcriptional profile between these two tissues. Conversely, out of 80 up-regulated genes, 68 (85\%) displayed a biased expression in the testes (Table 3), and only one (i.e. GMOY011112) in the MAGs. The remaining 11 genes (14\%) displayed an unbiased transcriptional profile between these two tissues.

\section{Absence of symbionts affects genes which are maturation and mating-responsive}

The genes affected by the removal of the symbionts were cross-referenced to separate libraries derived from MAGs and testes collected from $\mathrm{Gmm}^{\mathrm{WT}}$ males at different sexual maturation and mating states. These libraries were derived from reproductively immature teneral flies, mature unmated and mature mated flies (6-8 h post mating) [3]. Genes were categorized as maturation- or mating-responsive using the Kal's Z-test [30] (with FDR $<0.05$ ) when displaying a fold change ratio $>2$ (i.e. up-regulated in response to maturation/mating) and fold change ratio $<$ 0.5 (i.e. down-regulated in response to maturation/mating). We found that, in $\mathrm{Gmm}^{\mathrm{WT}}$ males, the expression of a proportion of the $\mathrm{Gmm}^{\text {Apo }}$ responsive genes (both down- and up-regulated) was also affected by sexual maturation (78\%, $n=43$; and $62 \%, n=50$, respectively) (Figs. 3, 4). The majority of genes down-regulated in the aposymbiotic state were, in presence of symbionts (i.e. in $\mathrm{Gmm}^{\text {WT }}$ males), up-regulated in response to sexual maturation $(65 \%, n=28)$, and were mostly MAG-biased $(n=17)$. Among these, GMOY002708, homogentisate 1,2-dioxygenase - GMOY006073, and GMOY011540 displayed a particularly high increase in response to maturation in the presence of symbionts (i.e. fold change of 6.4, 6.7, and 12.4, respectively) (Additional file 7). In contrast, the great majority of genes up-regulated in the aposymbiotic state $(92 \%, n=46)$ were, in the presence of symbionts (i.e. in $\mathrm{Gmm}^{\mathrm{WT}}$ males), down-regulated in response to sexual maturation, and were mostly testes-biased $(n=35)$. Among 


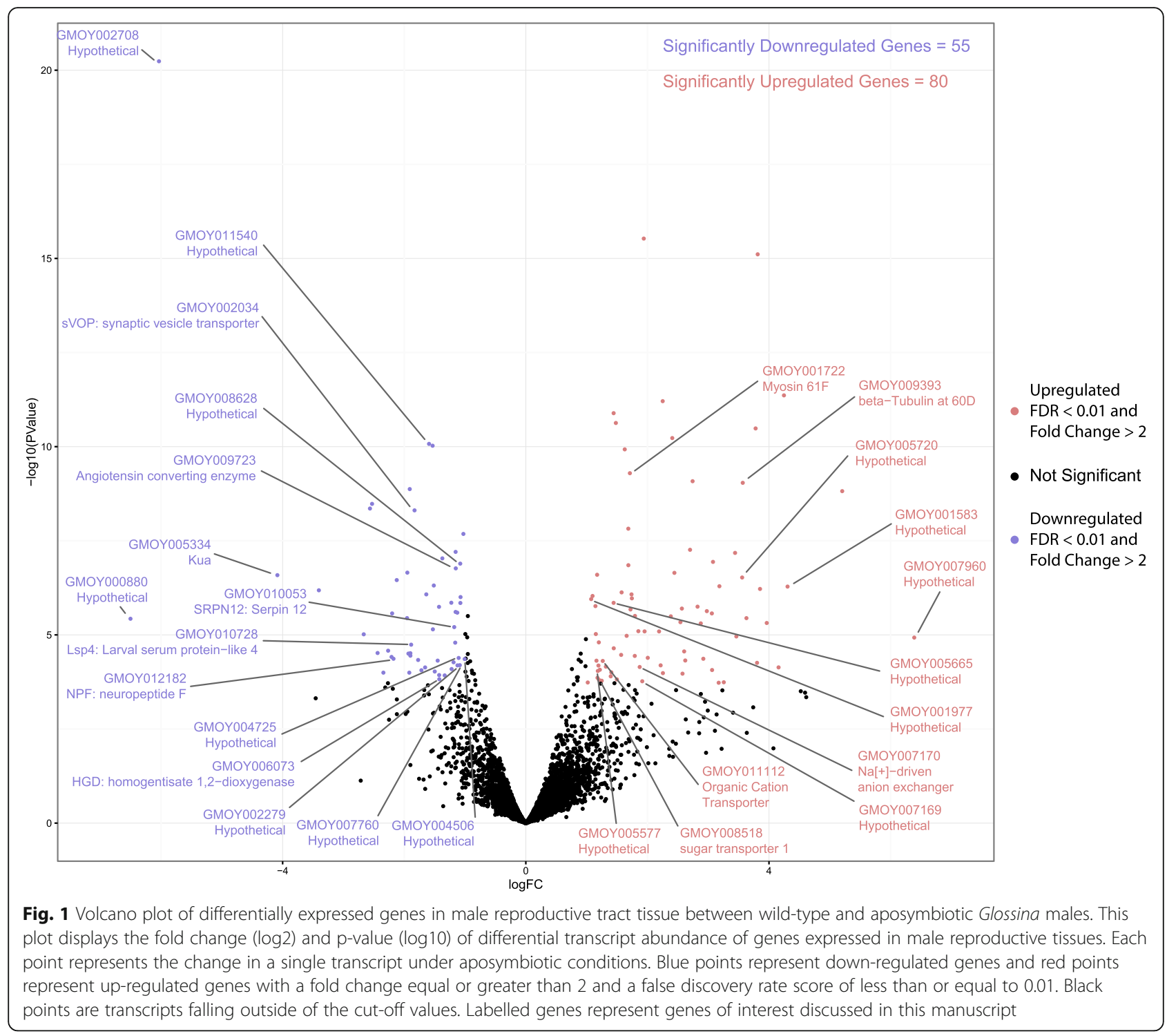

these, there is the GMOY007960 gene, with yet unknown function, which showed the greatest decrease in response to maturation in normal males (45.8-fold change).

The presence of symbionts also affects expression of mating-responsive genes in both MAGs and testes (Figs. 2, 3). Indeed, in Gmm ${ }^{\text {WT }}$ males, the genes we found to be down-regulated by symbiont removal displayed a trend of increased transcription after mating $(89 \%, n=49)$, particularly in the MAGs $(41 \%, 20)$. This is particularly evident in the case of the genes GMOY000880, and kua GMOY005334. In contrast, the $\mathrm{Gmm}^{\mathrm{Apo}}$ up-regulated genes displayed decreased transcription after mating $(81 \%, n=65)$, particularly in the testes $(n=57)$. Nineteen testes-biased genes displayed a particularly intense decrease in their transcription in response to mating (i.e. fold change $>50$ ), and they include the Zinc transporter 35C - GMOY005720, GMOY007169, the $\mathrm{Na}[+]$-driven anion exchanger - GMOY007170, myosin 61F GMOY001722, and the tubulin beta 3 - GMOY009393.

\section{Genes which contribute to ejaculate production are down-regulated in the absence of symbionts}

Among the genes displaying a significant down-regulation in $\mathrm{Gmm}^{\mathrm{Apo}}$ males, we found eight transcripts that encode spermatophore proteins [3]. They included seven MAGbiased genes, namely two novel tsetse genes (i.e. GMOY004506 and GMOY007760), three genes with predicted serine protease inhibitor activity (i.e. GMOY002279, GMOY004725, and SRPN12 - GMOY010053), one sequence with unknown function (i.e. GMOY008628), and the Angiotensin converting enzyme gene (Ance GMOY009723) (Additional file 3). Interestingly, none of the $\mathrm{Gmm}^{\mathrm{Apo}}$ up-regulated genes encode proteins transferred in the spermatophore. 
Table 1 Twenty-two down-regulated genes in Gmm ${ }^{\text {Apo }}$ males showing a MAG-biased profile in Gmm ${ }^{\text {WT }}$ males

\begin{tabular}{|c|c|c|c|c|c|}
\hline Vectorbase gene ID & Vectorbase Description & Best $n r$ BLASTx Hit & Accession & $\begin{array}{l}\text { BLASTx } \\
\text { E-Value }\end{array}$ & $\begin{array}{l}\text { MAGs/Testes } \\
\text { fold change }\end{array}$ \\
\hline GMOY000880 & & $\begin{array}{l}\text { hypothetical protein FF38_03138, partial } \\
\text { [Lucilia cuprina] }\end{array}$ & KNC27735.1 & $7.00 \mathrm{E}-79$ & 14.90 \\
\hline GMOY002216 & & $\begin{array}{l}\text { PREDICTED: uncharacterized protein } \\
\text { LOC101892654 isoform X4 [Musca domestica] }\end{array}$ & XP_019890273.1 & 0.0 & 7.26 \\
\hline GMOY002279 & & $\begin{array}{l}\text { PREDICTED: male accessory gland serine } \\
\text { protease inhibitor [Musca domestica] }\end{array}$ & XP_005182681.1 & 5.00E-11 & 72.55 \\
\hline GMOY002397 & & hypothetical protein FF38_12465 [Lucilia cuprina] & KNC32328.1 & $5.00 \mathrm{E}-15$ & 35.33 \\
\hline GMOY002708 & & $\begin{array}{l}\text { PREDICTED: uncharacterized protein } \\
\text { LOC101890794 isoform X4 [Musca domestica] }\end{array}$ & XP_005190518.1 & 1.00E-14 & 44.56 \\
\hline GMOY004506 & & no hits & & & 117.35 \\
\hline GMOY004725 & & $\begin{array}{l}\text { PREDICTED: male accessory gland serine } \\
\text { protease inhibitor-like [Stomoxys calcitrans] }\end{array}$ & XP_013110809.1 & 7.00E-19 & 133.03 \\
\hline GMOY005334 & Kua & $\begin{array}{l}\text { PREDICTED: transmembrane protein } \\
189 \text { [Stomoxys calcitrans] }\end{array}$ & XP_013101683.1 & $3.00 \mathrm{E}-167$ & 28.86 \\
\hline GMOY005914 & & $\begin{array}{l}\text { hypothetical protein FF38_03123, } \\
\text { partial [Lucilia cuprina] }\end{array}$ & KNC27757.1 & 0.0 & 5.32 \\
\hline GMOY006073 & $\begin{array}{l}\text { HGD: homogentisate } \\
\text { 1,2-dioxygenase }\end{array}$ & $\begin{array}{l}\text { homogentisate 1,2-dioxygenase } \\
\text { [Lucilia cuprina] }\end{array}$ & KNC25382.1 & 0.0 & 14.27 \\
\hline GMOY006405 & $\begin{array}{l}\text { Ecdysone-inducible } \\
\text { gene E3 }\end{array}$ & $\begin{array}{l}\text { PREDICTED: uncharacterized protein } \\
\text { LOC106621464 [Bactrocera oleae] }\end{array}$ & XP_014095828.1 & $6.00 \mathrm{E}-88$ & 26.08 \\
\hline GMOY006513 & $\begin{array}{l}\text { Zinc/iron regulated transporter- } \\
\text { related protein } 42 C .2\end{array}$ & $\begin{array}{l}\text { putative zinc transporter } 4 \text { ic-like } \\
\text { protein [Haematobia irritans] }\end{array}$ & JAV17535.1 & $6.00 \mathrm{E}-138$ & 16.99 \\
\hline GMOY007760 & & no hits & & & 95.61 \\
\hline GMOY008628 & & $\begin{array}{l}\text { hypothetical protein FF38_13303 } \\
\text { [Lucilia cuprina] }\end{array}$ & KNC29468.1 & $6.00 \mathrm{E}-16$ & 56.42 \\
\hline GMOY009723 & $\begin{array}{l}\text { Angiotensin converting } \\
\text { enzyme }\end{array}$ & $\begin{array}{l}\text { angiotensin-converting enzyme } \\
\text { [Lucilia cuprina] }\end{array}$ & KNC21161.1 & 0.0 & 33.37 \\
\hline GMOY010053 & $\begin{array}{l}\text { SRPN12: serine protease } \\
\text { inhibitor (serpin) } 12\end{array}$ & $\begin{array}{l}\text { PREDICTED: antichymotrypsin-2-like } \\
\text { isoform X14 [Stomoxys calcitrans] }\end{array}$ & XP_013104701.1 & 4.00E-56 & 84.59 \\
\hline GMOY010303 & & $\begin{array}{l}\text { PREDICTED: serine protease inhibitor } \\
\text { Kazal-type } 1 \text { [Musca domestica] }\end{array}$ & XP_005190386.1 & $3.00 \mathrm{E}-17$ & 5.77 \\
\hline GMOY010506 & Putative thioesterase & $\begin{array}{l}\text { PREDICTED: protein THEM6 } \\
\text { [Musca domestica] }\end{array}$ & XP_005178985.1 & $3.00 \mathrm{E}-100$ & 21.19 \\
\hline GMOY010906 & kokopelli & $\begin{array}{l}\text { hypothetical protein FF38_08330, } \\
\text { partial [Lucilia cuprina] }\end{array}$ & KNC25973.1 & 4.00E-118 & 45.56 \\
\hline GMOY011540 & & $\begin{array}{l}\text { putative uridine phosphorylase } \\
\text { [Haematobia irritans] }\end{array}$ & JAV16233.1 & $6.00 \mathrm{E}-137$ & 17.48 \\
\hline GMOY012067 & Putative salivary secreted peptide & no hits & & & 258.22 \\
\hline GMOY012281 & & odorant binding protein [Calliphora stygia] & AID61309.1 & $9.00 \mathrm{E}-04$ & 20.09 \\
\hline
\end{tabular}

Table 2 Five down-regulated genes in $\mathrm{Gmm}^{\mathrm{Apo}}$ males showing a testes-biased profile in $\mathrm{Gmm}^{\mathrm{WT}}$ males

\begin{tabular}{|c|c|c|c|c|c|}
\hline Vectorbase gene ID & Vectorbase Description & Best $n r$ BLASTx Hit & Accession & BLAST_E-Value & $\begin{array}{l}\text { Testes/MAGs } \\
\text { fold change }\end{array}$ \\
\hline GMOY002034 & $\begin{array}{l}\text { synaptic vesicle } \\
\text { transporter }\end{array}$ & $\begin{array}{l}\text { hypothetical protein FF38_11887 } \\
\text { [Lucilia cuprina] }\end{array}$ & KNC24952.1 & 0.0 & 613.26 \\
\hline GMOY008588 & & no hits & & & 5.66 \\
\hline GMOY011064 & & hypothetical protein FF38_07287 [Lucilia cuprina] & KNC32510.1 & 0.0 & 6.06 \\
\hline GMOY011412 & Aldehyde oxidase & $\begin{array}{l}\text { PREDICTED: indole-3-acetaldehyde oxidase } \\
\text { [Musca domestica] }\end{array}$ & XP_019893881.1 & 0.0 & 5.59 \\
\hline GMOY012182 & NPF: neuropeptide F & hypothetical protein FF38_11880 [Lucilia cuprina] & KNC24956.1 & $7,00 \mathrm{E}-23$ & 193.57 \\
\hline
\end{tabular}


Table 3 Sixty-eight up-regulated genes in $\mathrm{Gmm}^{\text {Apo }}$ males showing a testes-biased profile in Gmm ${ }^{\text {WT }}$ males

\begin{tabular}{|c|c|c|c|c|c|}
\hline $\begin{array}{l}\text { Vectorbase } \\
\text { gene ID }\end{array}$ & $\begin{array}{l}\text { Vectorbase } \\
\text { Description }\end{array}$ & Best $n r$ BLASTx Hit & Accession & $\begin{array}{l}\text { BLAST_E- } \\
\text { Value }\end{array}$ & $\begin{array}{l}\text { Testes/MAGs } \\
\text { fold change }\end{array}$ \\
\hline GMOY000619 & Tetraspanin & hypothetical protein FF38_09930 [Lucilia cuprina] & KNC31071.1 & $3.00 \mathrm{E}-99$ & 48.83 \\
\hline GMOY000812 & & $\begin{array}{l}\text { PREDICTED: glucose dehydrogenase [FAD, quinone] } \\
\text { [Musca domestica] }\end{array}$ & XP_005186034.1 & 0.0 & 72.42 \\
\hline GMOY001391 & $\begin{array}{l}\text { SCARA5: Scavenger } \\
\text { Receptor Class A, } \\
\text { Member } 5\end{array}$ & hypothetical protein FF38_05500 [Lucilia cuprina] & KNC27261.1 & 0.0 & 33.83 \\
\hline GMOY001583 & & integrin alpha-PS3 [Lucilia cuprina] & KNC31990.1 & 4.00E-17 & 135.91 \\
\hline GMOY001722 & Myosin $61 \mathrm{~F}$ & myosin-IB [Lucilia cuprina] & KNC31972.1 & 0.0 & 40.45 \\
\hline GMOY001794 & fused lobes & putative beta-hexosaminidase fdl [Lucilia cuprina] & KNC26699.1 & 0.0 & 10.42 \\
\hline GMOY001977 & & hypothetical protein FF38_05070 [Lucilia cuprina] & KNC29694.1 & 0.0 & 23.94 \\
\hline GMOY002057 & & hypothetical protein FF38_02107 [Lucilia cuprina] & KNC28398.1 & 0.0 & 6.40 \\
\hline GMOY002247 & nord & $\begin{array}{l}\text { PREDICTED: uncharacterized protein LOC101887233 } \\
\text { [Musca domestica] }\end{array}$ & XP_005185286.1 & 0.0 & 14.60 \\
\hline GMOY002466 & & peroxidase [Lucilia cuprina] & KNC34773.1 & 0.0 & 25.87 \\
\hline GMOY002491 & & protein takeout [Lucilia cuprina] & KNC23528.1 & $2.00 \mathrm{E}-67$ & 44.31 \\
\hline GMOY002881 & & hypothetical protein FF38_01910 [Lucilia cuprina] & KNC34784.1 & 1.00E-174 & 223.02 \\
\hline GMOY002886 & & no hits & & & 13.05 \\
\hline GMOY002911 & & hypothetical protein FF38_03087 [Lucilia cuprina] & KNC32537.1 & $8.00 \mathrm{E}-67$ & 7.46 \\
\hline GMOY003353 & & PREDICTED: arylsulfatase B [Musca domestica] & XP_005176719.1 & 0.0 & 61.33 \\
\hline GMOY003366 & & $\begin{array}{l}\text { PREDICTED: C-1-tetrahydrofolate synthase, cytoplasmic isoform } \\
\text { X3 [Musca domestica] }\end{array}$ & XP_005183706.1 & 0.0 & 36.28 \\
\hline GMOY004222 & $\begin{array}{l}\text { GluR-gf3: ionotropic } \\
\text { glutamate receptor }\end{array}$ & hypothetical protein FF38_07882 [Lucilia cuprina] & KNC24884.1 & 0.0 & 10.41 \\
\hline GMOY004447 & & hypothetical protein FF38_11623 [Lucilia cuprina] & KNC30614.1 & 0.0 & 119.17 \\
\hline GMOY005165 & croquemort & protein croquemort [Ceratitis capitata] & JAB88784.1 & 0.0 & 20.13 \\
\hline GMOY005282 & knickkopf & protein Skeletor, isoforms B/C [Ceratitis capitata] & JAB97494.1 & 0.0 & 40.21 \\
\hline GMOY005361 & & hypothetical protein FF38_09491 [Lucilia cuprina] & KNC22549.1 & $1.00 \mathrm{E}-68$ & 72.52 \\
\hline GMOY005449 & & hypothetical protein FF38_14542 [Lucilia cuprina] & KNC32042.1 & $3.00 \mathrm{E}-47$ & 50.27 \\
\hline GMOY005537 & & $\begin{array}{l}\text { PREDICTED: uncharacterized protein LOC106095798 isoform } \\
\text { X1 [Stomoxys calcitrans] }\end{array}$ & XP_013118620.1 & 0.0 & 241.75 \\
\hline GMOY005573 & acid sphingomyelinase & hypothetical protein FF38_09213 [Lucilia cuprina] & KNC33883.1 & 0.0 & 15.57 \\
\hline GMOY005577 & & $\begin{array}{l}\text { calcium-binding mitochondrial carrier protein Aralar1 } \\
\text { [Lucilia cuprina] }\end{array}$ & KNC20798.1 & 0.0 & 15.44 \\
\hline GMOY005665 & & $\begin{array}{l}\text { PREDICTED: uncharacterized protein LOC106084900 } \\
\text { [Stomoxys calcitrans] }\end{array}$ & XP_013104316.1 & 0.0 & 52.40 \\
\hline GMOY005720 & Zinc transporter $35 \mathrm{C}$ & PREDICTED: zinc transporter 2-like [Aedes albopictus] & XP_019550545.1 & 2.00E-92 & 178.93 \\
\hline GMOY006369 & & hypothetical protein FF38_03491 [Lucilia cuprina] & KNC32157.1 & 0.0 & 17.61 \\
\hline GMOY006417 & $\begin{array}{l}\text { OBP20: odorant } \\
\text { binding protein } 20\end{array}$ & putative odorant binding protein 20 [Haematobia irritans] & JAV15842.1 & $9.00 \mathrm{E}-46$ & 37.48 \\
\hline GMOY006503 & Beta-hexosaminidase & $\begin{array}{l}\text { PREDICTED: chitooligosaccharidolytic beta-N- } \\
\text { acetylglucosaminidase [Musca domestica] }\end{array}$ & XP_005182019.1 & 0.0 & 133.63 \\
\hline GMOY006539 & & $\begin{array}{l}\text { PREDICTED: alpha-1,6-mannosyl-glycoprotein 2-beta-N- } \\
\text { acetylglucosaminyltransferase isoform X3 [Stomoxys calcitrans] }\end{array}$ & XP_013099543.1 & $8.00 \mathrm{E}-126$ & 106.67 \\
\hline GMOY006677 & $\begin{array}{l}\text { Solute:Sodium } \\
\text { Symporter }\end{array}$ & hypothetical protein FF38_06448 [Lucilia cuprina] & KNC34106.1 & 0.0 & 58.69 \\
\hline GMOY006713 & & CG8192 [Drosophila buscki] & ALC41544.1 & 2.00E-90 & 82.52 \\
\hline GMOY006818 & & PREDICTED: lipoma HMGIC fusion partner-like 2 protein & XP_013119103.1 & $3.00 \mathrm{E}-118$ & 34.98 \\
\hline
\end{tabular}


Table 3 Sixty-eight up-regulated genes in $\mathrm{Gmm}^{\text {Apo }}$ males showing a testes-biased profile in $\mathrm{Gmm}^{\mathrm{WT}}$ males (Continued)

\begin{tabular}{|c|c|c|c|c|c|}
\hline $\begin{array}{l}\text { Vectorbase } \\
\text { gene ID }\end{array}$ & $\begin{array}{l}\text { Vectorbase } \\
\text { Description }\end{array}$ & Best $n r$ BLASTx Hit & Accession & $\begin{array}{l}\text { BLAST_E- } \\
\text { Value }\end{array}$ & $\begin{array}{l}\text { Testes/MAGs } \\
\text { fold change }\end{array}$ \\
\hline GMOY006875 & & PREDICTED: alkaline phosphatase [Musca domestica] & XP_011291521.2 & 0.0 & 109.75 \\
\hline GMOY006952 & $\begin{array}{l}\text { Major Facilitator } \\
\text { Superfamily } \\
\text { transporter }\end{array}$ & Organic cation transporter-like protein [Lucilia cuprina] & KNC25680.1 & 0.0 & 103.42 \\
\hline GMOY006960 & & $\begin{array}{l}\text { PREDICTED: venom acid phosphatase Acph-1 } \\
\text { [Stomoxys calcitrans] }\end{array}$ & XP_013110448.1 & 0.0 & 22.63 \\
\hline GMOY007021 & & putative inorganic phosphate cotransporter [Lucilia cuprina] & KNC32863.1 & 0.0 & 65.17 \\
\hline GMOY007046 & & hypothetical protein FF38_01733 [Lucilia cuprina] & KNC29857.1 & 0.0 & 35.81 \\
\hline GMOY007169 & & hypothetical protein FF38_08034 [Lucilia cuprina] & KNC22811.1 & $7.00 \mathrm{E}-24$ & 150.00 \\
\hline GMOY007170 & $\begin{array}{l}\mathrm{Na}[+] \text {-driven anion } \\
\text { exchanger }\end{array}$ & $\begin{array}{l}\text { PREDICTED: electroneutral sodium bicarbonate exchanger } \\
1 \text { isoform X1 [Stomoxys calcitrans] }\end{array}$ & XP_013100613.1 & 0.0 & 74.61 \\
\hline GMOY007305 & & PREDICTED: Iysozyme [Drosophila suzukii] & XP_016927878.1 & $2.00 \mathrm{E}-57$ & 41.88 \\
\hline GMOY007468 & & hypothetical protein FF38_04128 [Lucilia cuprina] & KNC22753.1 & $3.00 \mathrm{E}-63$ & 114.27 \\
\hline GMOY007532 & & $\begin{array}{l}\text { putative leucine-rich repeat-containing g-protein coupled } \\
\text { receptor } 5 \text { [Haematobia irritans] }\end{array}$ & JAV16303.1 & 0.0 & 77.95 \\
\hline GMOY007691 & PAK-kinase & $\begin{array}{l}\text { PREDICTED: serine/threonine-protein kinase PAK } 1 \text { isoform } \\
\text { X1 [Stomoxys calcitrans] }\end{array}$ & XP_013099440.1 & 0.0 & 42.00 \\
\hline GMOY007960 & & $\begin{array}{l}\text { PREDICTED: endothelin-converting enzyme } 1 \\
\text { [Stomoxys calcitrans] }\end{array}$ & XP_013119452.1 & 0.0 & 187.13 \\
\hline GMOY008133 & & $\begin{array}{l}\text { PREDICTED: uncharacterized protein LOC101894637 } \\
\text { [Musca domestica] }\end{array}$ & XP_005176834.1 & 0.0 & 11.70 \\
\hline GMOY008518 & sugar transporter 1 & hypothetical protein FF38_06053, partial [Lucilia cuprina] & KNC33316.1 & 0.0 & 12.53 \\
\hline GMOY008765 & spalt major & homeotic protein spalt-major [Lucilia cuprina] & KNC31339.1 & 0.0 & 100.83 \\
\hline GMOY009021 & & PREDICTED: protein D3-like [Bactrocera dorsalis] & XP_011197362.1 & $2.00 \mathrm{E}-85$ & 157.77 \\
\hline GMOY009202 & & hypothetical protein FF38_07050 [Lucilia cuprina] & KNC31716.1 & $1.00 \mathrm{E}-47$ & 55.01 \\
\hline GMOY009300 & & hypothetical protein FF38_11715 [Lucilia cuprina] & KNC30663.1 & 0.0 & 13.77 \\
\hline GMOY009393 & beta-Tubulin at 60D & tubulin beta-3 chain [Lucilia cuprina] & KNC22620.1 & 0.0 & 58.23 \\
\hline GMOY009759 & & hypothetical protein FF38_02940 [Lucilia cuprina] & KNC28936.1 & 0.0 & 100.36 \\
\hline GMOY009924 & & $\begin{array}{l}\text { PREDICTED: nuclear pore complex protein Nup133 isoform } \\
\text { X1 [Stomoxys calcitrans] }\end{array}$ & XP_013101194.1 & 0.0 & 13.86 \\
\hline GMOY010035 & Mig-2-like & $\begin{array}{l}\text { PREDICTED: ras-related C3 botulinum toxin substrate } 1 \\
\text { [Musca domestica] }\end{array}$ & XP_005183165.1 & $5.00 \mathrm{E}-143$ & 48.84 \\
\hline GMOY010039 & optix: optix & protein Optix [Lucilia cuprina] & KNC34851.1 & 0.0 & 346.87 \\
\hline GMOY010309 & $\begin{array}{l}\text { AASS: lysine- } \\
\text { ketoglutarate } \\
\text { reductase }\end{array}$ & hypothetical protein FF38_02955 [Lucilia cuprina] & KNC31958.1 & 0.0 & 8.79 \\
\hline GMOY010450 & $\begin{array}{l}\text { Trissin R: trissin } \\
\text { receptor }\end{array}$ & PREDICTED: 5-hydroxytryptamine receptor 1 [Bactrocera oleae] & XP_014086219.1 & 0.0 & 372.42 \\
\hline GMOY010478 & gl16235 & $\begin{array}{l}\text { PREDICTED: probable salivary secreted peptide } \\
\text { [Stomoxys calcitrans] }\end{array}$ & XP_013110315.1 & $3.00 \mathrm{E}-58$ & 30.94 \\
\hline GMOY010875 & $\begin{array}{l}\text { epithelial membrane } \\
\text { protein }\end{array}$ & $\begin{array}{l}\text { PREDICTED: scavenger receptor class B member } 1 \\
\text { [Musca domestica] }\end{array}$ & XP_005177855.1 & 0.0 & 69.64 \\
\hline GMOY011278 & $\begin{array}{l}\mathrm{Na}[+] / \mathrm{H}[+] \\
\text { hydrogen antiporter }\end{array}$ & hypothetical protein FF38_02922 [Lucilia cuprina] & KNC22346.1 & 0.0 & 35.31 \\
\hline GMOY011388 & & $\begin{array}{l}\text { PREDICTED: lactosylceramide 4-alpha-galactosyltransferase } \\
\text { [Stomoxys calcitrans] }\end{array}$ & XP_013100115.1 & 4.00E-136 & 37.41 \\
\hline GMOY011731 & yellow-h & hypothetical protein FF38_05398 [Lucilia cuprina] & KNC26088.1 & 0.0 & 19.11 \\
\hline GMOY011839 & & hypothetical protein [Ceratitis capitata] & JAB97045.1 & 0.0 & 6.89 \\
\hline GMOY011858 & & PREDICTED: mucin-17 [Stomoxys calcitrans] & XP_013110461.1 & $2.00 \mathrm{E}-156$ & 330.58 \\
\hline
\end{tabular}


Table 3 Sixty-eight up-regulated genes in $\mathrm{Gmm}^{\text {Apo }}$ males showing a testes-biased profile in $\mathrm{Gmm}^{\mathrm{WT}}$ males (Continued)

\begin{tabular}{|c|c|c|c|c|c|}
\hline $\begin{array}{l}\text { Vectorbase } \\
\text { gene ID }\end{array}$ & $\begin{array}{l}\text { Vectorbase } \\
\text { Description }\end{array}$ & Best $n r$ BLASTx Hit & Accession & $\begin{array}{l}\text { BLAST_E- } \\
\text { Value }\end{array}$ & $\begin{array}{l}\text { Testes/MAGs } \\
\text { fold change }\end{array}$ \\
\hline GMOY012079 & & PREDICTED: aquaporin [Rhagoletis zephyria] & XP_017484187.1 & $2.00 \mathrm{E}-74$ & 13.87 \\
\hline GMOY012085 & lazaro & putative phosphatidate phosphatase [Lucilia cuprina] & KNC34968.1 & $5.00 \mathrm{E}-126$ & 93.71 \\
\hline
\end{tabular}

\section{Discussion}

Glossina m. morsitans aposymbiotic males have been previously shown to display a reproductive fitness similar to normal males. Indeed, they were proven able to mate with $\mathrm{Gmm}^{\mathrm{WT}}$ females [12], transfer their ejaculate in the form of a spermatophore (Attardo, unpublished data), and spermatozoa were detected in the female spermathecae post-mating [12]. In addition, both larval deposition and adult progeny eclosion rates were not different from those recorded for $\mathrm{Gmm}^{\text {WT }}$ females mated to $\mathrm{Gmm}^{\mathrm{WT}}$ males [12]. However, given the tight relationships between tsetse and its three endosymbionts, which affect multiple aspects of fly biology including metabolism and immunity $[4,31]$, we expect that the removal of endosymbionts may affect to some extent also male reproductive functions. To begin addressing this knowledge gap, here we generated transcriptomes from the reproductive tissues of $\mathrm{Gmm}^{\mathrm{Apo}}$ and $\mathrm{Gmm}^{\mathrm{WT}}$ males and identified genes differentially expressed between these two statuses,

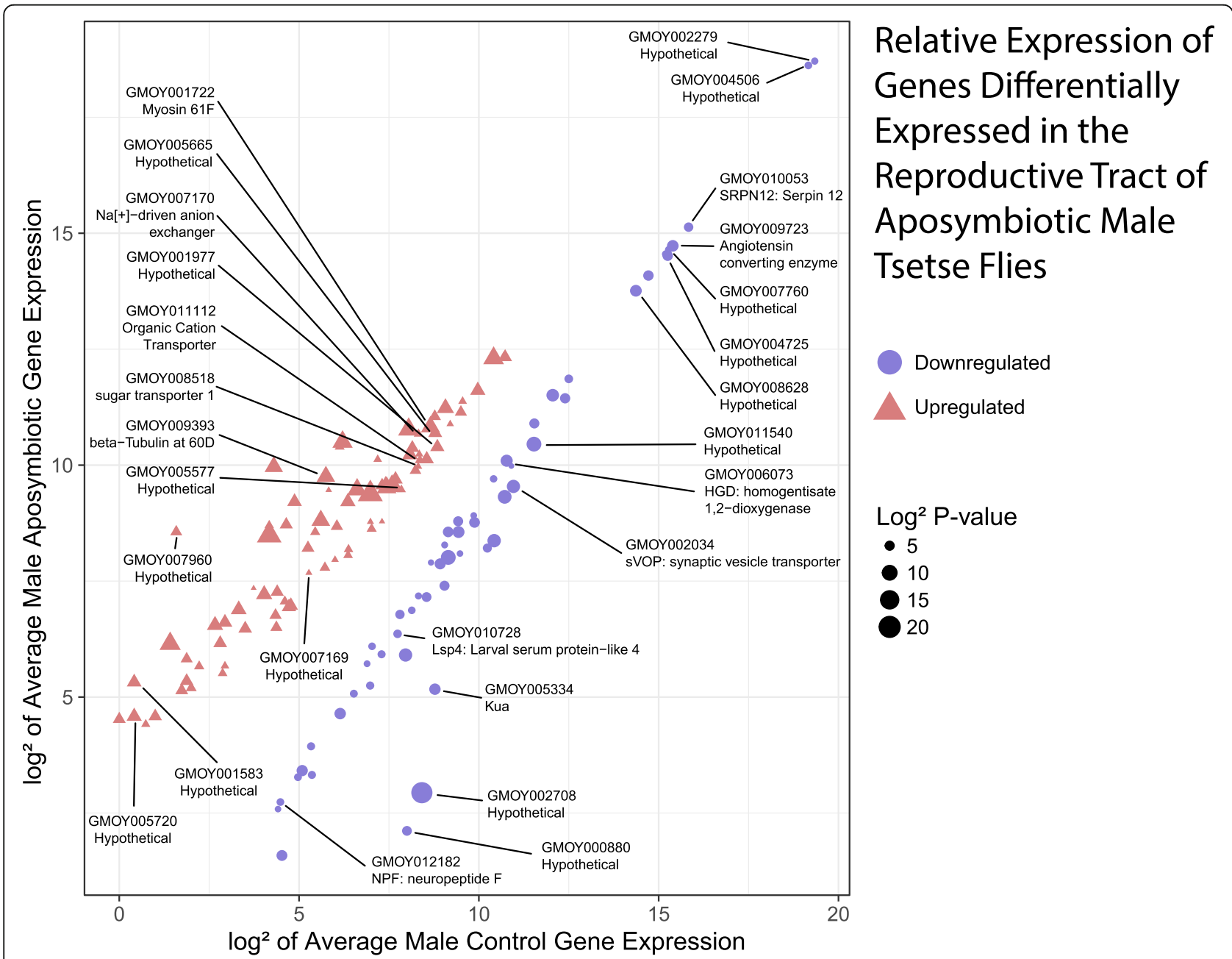

Fig. 2 Scatter plot illustrating the relative expression levels of male reproductive genes differentially expressed under aposymbiotic conditions. The $x$-axis represents the log2 of the counts per million (CPM) expression value for wild-type flies. The $y$-axis represents the log2 value of CPM value for aposymbiotic flies. Red triangles and blue circles represent genes up and down-regulated respectively under aposymbiotic conditions. Point size represents the log 2 of the $P$-value score for differential expression. Labelled points represent genes discussed in this manuscript 


\section{A) SEXUAL MATURATION}

$55 \mathrm{Gmm}^{\text {Apo }}$ down-regulated genes

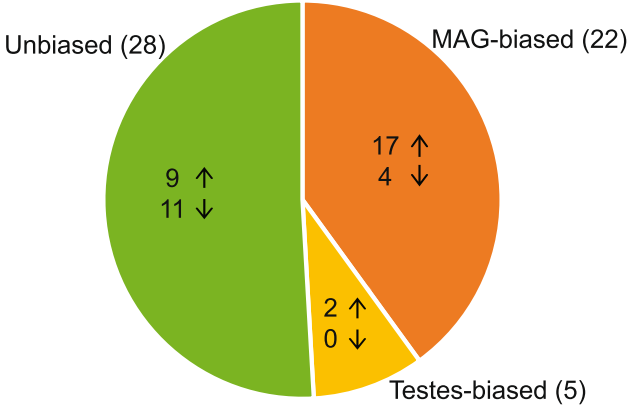

B) MATING

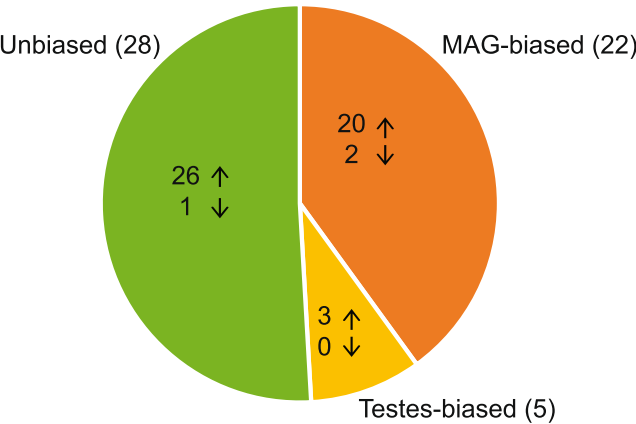

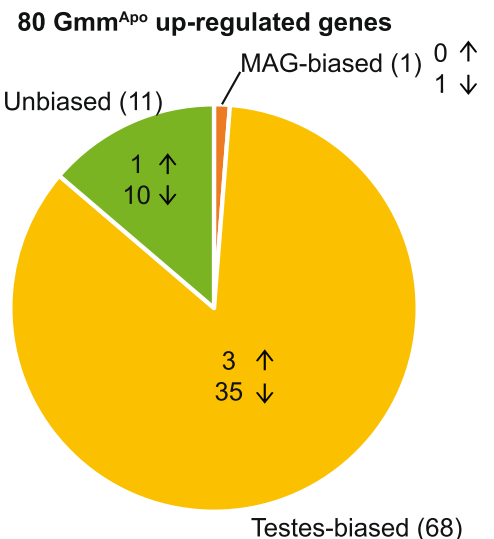

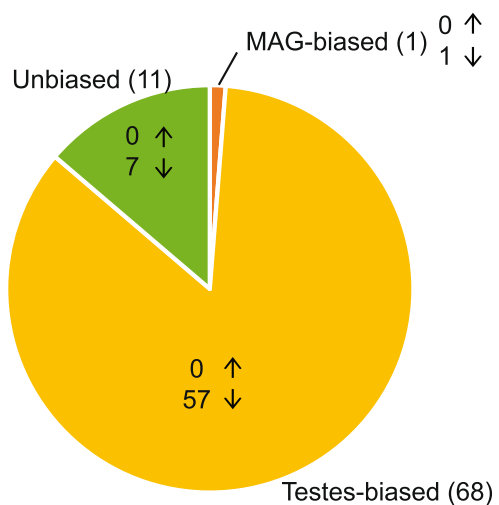

Fig. 3 Number of genes showing a maturation and mating-responsive transcriptional profile in $\mathrm{Gmm}^{\mathrm{WT}}$ male reproductive tissues. Arrows indicate up- or down-regulation in response to (a) sexual maturation or (b) mating. Genes are classified according to their biased expression profile in MAGs or testes

enlightening novel potentially relevant aspects of tsetse-symbionts interactions.

\section{Absence of symbionts depresses the activity of genes in the male accessory glands, including sequences encoding spermatophore proteins}

Functions related to immunity, mating, amino acid and nucleotide metabolism, and seminal fluid proteins were directly impacted by microbiota removal in the male accessory glands. One of these functions includes chitin binding. Proteins with chitin binding activity have been associated with antimicrobial roles [32], and are found in the seminal fluid of different insects [33-38]. Two tsetse genes, which are down-regulated in the absence of symbionts, encode proteins with predicted chitin binding activity in the MAGs. One of these is GMOY000880, which bears homology to the Drosophila predicted chitin-binding protein CG32036 [39], and the other is GMOY002708, which carries a chitin binding Peritrophin-A domain (pfam01607: CBM_14). Our previous data on $\mathrm{Gmm}^{\mathrm{WT}}$ males indicated that these two genes increase in transcription in response to mating, suggesting an immune-related activity in male reproductive function. The absence of symbionts negatively impacts the transcription of the Glossina kua gene (GMOY005334), which in Drosophila is involved in the induction of the long-term female post-mating response [40]. Whether the down-regulation of this gene impacts tsetse female post-mating behaviour remains an open question as very limited information is currently available regarding the tsetse post-mating response. In G. morsitans, female receptivity to remating is known to decline rapidly and almost disappear at about $48 \mathrm{~h}$ post-mating [41]. At the molecular level, transcription of some milk gland proteins has been found to be higher in mated and pregnant females than in unmated flies, suggesting that mating could contribute to the mechanism of milk protein activation [42].

Tyrosine detoxification is important for survival and reproduction of blood-feeding insects including kissing 


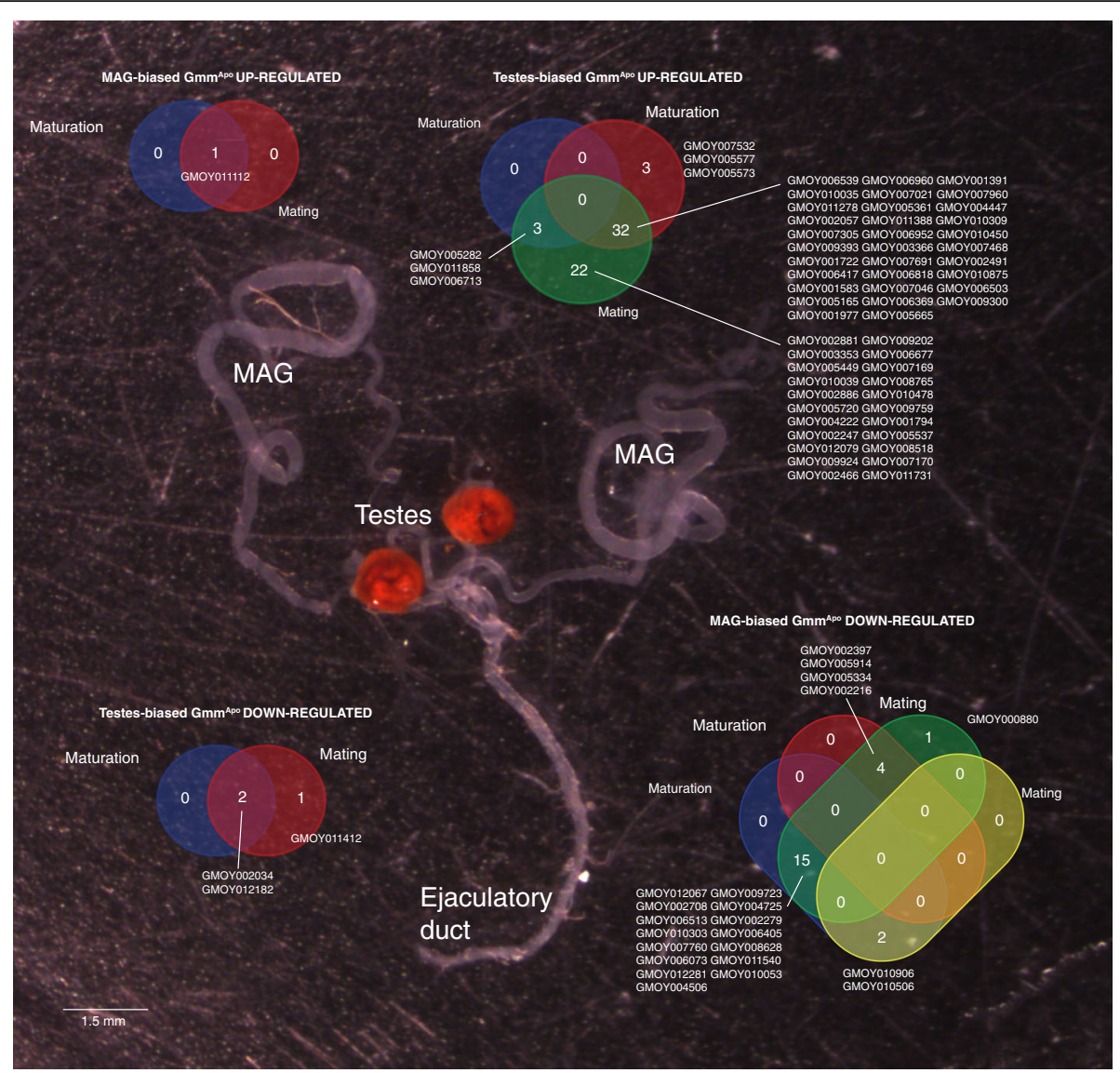

Fig. 4 Genes showing a maturation and mating-responsive transcriptional profile in Gmm ${ }^{W T}$ male reproductive tissues. The IDs of MAGs- and testes-biased genes are shown in Venn diagrams illustrating the number of common sequences found between four groups, i.e. up- or down-regulated in response to maturation and up- or down-regulated in response to mating, separately for MAGs and testes. A tsetse male reproductive tract is shown. Scale bar $=1.5 \mathrm{~mm}$

bugs, mosquitoes and ticks [43-45]. In tsetse, phenylalanine-tyrosine metabolism is one of the host metabolic pathways dependent on Wigglesworthia-derived vitamin products [4]. The homogentisate 1,2-dioxygenase ( $h g d$ ) GMOY006073 is predicted to encode an enzyme mediating the conversion of homogentisate to maleylacetoacetate, a step in the catabolism of both tyrosine and phenylalanine (InterPro IPR005708). Here we found that hgd is down-regulated in the aposymbiotic state and this may be a consequence of a compromised vitamin metabolism due to the absence of the mutualistic symbionts in the $\mathrm{Gmm}^{\text {Apo }}$ line investigated. Similarly, tsetse GMOY011540 is a putative uridine phosphorylase participating in the pathways of pyrimidine ribonucleosides degradation and salvage. Its down-regulation in $\mathrm{Gmm}^{\text {Apo }}$ males may also result from the absence of Wigglesworthia, which has been proposed to assist with production of nucleotides and metabolic intermediates essential for enriched nucleotide salvage pathways $[4,46]$.

Only a few testes-biased genes are down-regulated in $\mathrm{Gmm}^{\mathrm{Apo}}$ males. These include the neuropeptide F (NPF)
GMOY012182, which, in other insects, play important roles in reproductive physiology. In Drosophila, NPF is involved in courtship behavior [47]. In the desert locust, Schistocerca gregaria, NPF is related to testis and seminal vesicle size, and may affect the biochemical composition of the seminal fluid [48]. GMOY002034 is an evolutionarily conserved SVOP synaptic vesicle transporter $[49,50]$. This tsetse gene displays a sugar transporter domain. As such, it could affect the level of sugars in the ejaculate, promoting sperm motility, as proposed for Drosophila and as occurring in honey bees and vertebrates [40,51].

The absence of symbionts also results in reduced transcript abundance of MAG associated genes found to encode spermatophore components in $\mathrm{Gmm}^{\mathrm{WT}}$ flies. Among these, we identified genes showing serpin protease inhibitor (serpin) activity, such as GMOY002279, GMOY004725 and SRPN12. Serpins are the most common class of protease inhibitors in insect seminal fluid, where they play several sperm-related roles, including the mediation of sperm competition success through regulation of fertilizing capacity [52-54]. On the basis of their 
orthology to Drosophila CG16713, we could suggest the involvement of GMOY002279 and GMOY004725 in immune system responses. The presence of proteins with immune activity is not unexpected in insect seminal fluid [55-61], where they may play a protective role within the mated female reproductive tract potentially contributing to clear microbial pathogens introduced during mating $[62,63]$. Indeed, CG16713, which encodes a serine protease inhibitor of the Kunitz family, is up-regulated by microbial (both bacterial, fungal, and parasitoid) infection [64-66]. Both GMOY002279 and GMOY004725 carry a Kunitz/Bovine pancreatic trypsin inhibitor domain (pfam00014) and, since in invertebrates Kunitz inhibitors are involved in a range of physiological processes including blood coagulation, fibrinolysis, inflammation and ion channel blocking, these tsetse genes may be involved in the defence against microbes in female reproductive tissues after mating [67]. Another gene potentially involved in tsetse immunity may be SRPN12. The Drosophila ortholog of this gene, Serpin $42 \mathrm{Da}$, was proposed as essential for immune defence by inhibiting several pathogenic proteolytic enzymes, due to its ability to encode for multiple protein isoforms $[68,69]$. The Larval serum protein-like 4 gene - GMOY010728, unbiased in its expression between MAGs and testes in $\mathrm{Gmm}^{\mathrm{WT}}$ males, is ortholog to pro-phenol oxidase A1 in Drosophila. This protein is proposed to be involved in defensive melanization responses, and is moderately up-regulated upon Spiroplasma infection [70, 71]. The novel tsetse proteins GMOY007760 and GMOY008628, although not displaying any conserved protein domains, carry predicted O-linked glycosylated sites. Mucin-type O-glycosylation is an evolutionary conserved protein modification and it occurs in secreted proteins involved in recognition, adhesion and cell communication events [72], suggesting that these tsetse gene products may have potential carbohydrate-mediated cell adhesion roles to support sperm function in mated females. Proteins involved in cell to cell adhesion are indeed important for fertilization in mice [73-75], and have been identified also in the seminal fluid of the tiger mosquito Aedes albopictus [76].

The other novel tsetse gene GMOY004506 encodes one of the six proteins that account for $50 \%$ of the spermatophore proteome [3]. Due to the abundance of its protein, GMOY004506 may play a role in the formation of the spermatophore wall. The down-regulation of the corresponding gene may have an impact on spermatophore formation/sperm transfer in $\mathrm{Gmm}^{\mathrm{Apo}}$ males, potentially affecting sperm function. The Ance gene (GMOY009723), which is down-regulated in the absence of symbionts, may play an active role in spermatid differentiation in tsetse, as occurs in Drosophila [77]. This gene is proposed to be involved in the interaction between Wolbachia and their hosts [20,78], and it could contribute to the Cytoplasmic
Incompatibility (CI) phenotype [78]. In particular, in wRi-infected Drosophila cells, Ance was upregulated by Wolbachia infection [78], although this effect was not detected upon infection in Anopheles [79].

\section{Absence of symbionts activates gene expression in the testes} The up-regulated genes in $\mathrm{Gmm}^{\mathrm{Apo}}$ male reproductive tissues mostly included sequences with a testes-biased transcriptional profile. These gene products are related to transport, microtubule-related structural functions, neuropeptide reception, and energy metabolism.

Several predicted transporter genes are up-regulated in the absence of symbionts. They include genes whose products are predicted to be involved in the transport of amino acids (aspartate and glutamate, in the case of the putative ortholog of aralar1 - GMOY005577), ions and anions (GMOY005720, GMOY007169, GMOY007170), and sugars (GMOY008518). In the absence of the obligate Wigglesworthia symbionts, hemolymph levels of amino acids are significantly lower and carbohydrate metabolism is impaired [4]. The up-regulation of these transporters could be a response to conditions in which nutrients required for testes function are deficient. The over-expression of these genes could be an attempt by the tissue to compensate for lack of nutrients. Interestingly, the only MAG-biased gene up-regulated in $\mathrm{Gmm}^{\text {Apo }}$ males is a predicted organic cation transporter which, as its Drosophila ortholog CG6126, may affect the sugar levels in the seminal fluid as described above.

Among the testes-biased microtubule-related structural genes, we identified three up-regulated genes, myosin $I B$, bitesize and tubulin $\beta 3$. Myosin IB (GMOY001722), as its Drosophila counterpart (Myo61F), could be involved in regulating the actin-dependent post-Golgi trafficking of cargo [80]. Bitesize (GMOY001977) in Drosophila is expressed in epithelial tissues and controls the organization of actin filaments [81, 82]. Tubulin $\beta 3$ (betaTub60D) up-regulation may suggest a disruption of normal axoneme assembly. In Drosophila, Tubulins are distributed very specifically in the testes, with tubulin $\beta 3$ being transiently expressed during mid-embryogenesis and then exclusively in cytoplasmic microtubules of somatic cells in the gonads [83, 84].

The up-regulation of genes involved in cell adhesion, such as GMOY005665 and GMOY001583, may be related to an abnormal development of germ cells. Indeed, disruption of cell-cell connections is associated with impaired sperm development and function $[85,86]$. This may be the case of GMOY005665, whose best hit is the testis-specific gene CG5758, which was identified in the sperm proteome of Drosophila [87]. GMOY005665, as well as CG5758, carries two beta-Ig-H3/fasciclin domains (K8EG83) that are predicted to be involved in cell adhesion. The $\alpha$-PS3 
integrin scab (GMOY001583) is also involved in the regulation of adhesion, signaling, polarity and cell migration.

Potentially involved with sperm function/mobility is GMOY007960, whose best hit is the predicted endothelin-converting enzyme 1 (ECE-1) from Stomoxys calcitrans. In humans, ECE-1, a key enzyme in the biosynthesis of active endotelin-1 (ET-1), has been identified in prostate [88] and rat vas deferens [89]. ECE-1 transcription levels are particularly high in the Leydig cells of the human testis [90] and human seminal fluid is known to contain endothelin, which is proposed to stimulate the transport of sperm through the uterine cavity [91, 92]. In Drosophila, ECE-1 protein was identified in the sperm proteome [87].

\section{Conclusions}

The results of this work revealed distinctive trends in gene differential expression in accessory glands and testes of $\mathrm{Gmm}^{\text {Apo }}$ males. This may be related to the fact that these two organs participate in the maintenance of complementary reproductive functions in insects. In the testes, key regulatory genes involved in spermatogenesis and sperm function tend to be conserved to guarantee the male-specific processes required for gamete production [93, 94]. However, genes in the male accessory glands are more involved in ensuring male reproductive success through the production of seminal components with effects on female post-mating response [95]. Our data suggest a role for symbionts in contributing to the proper function of these two tissues. In the MAGs, symbionts appear to affect the expression of genes related to mating, immunity and seminal fluid component synthesis. In the testes, the absence of symbionts depresses the activity of genes involved in the metabolic apparatus at the basis of male reproduction, such as sperm production, motility and function. From an applied perspective, unravelling the metabolic and functional relationships between tsetse male and its symbionts will provide basic information useful to improve Sterile Insect Technique (SIT) based programs. In particular, a deeper knowledge of the interdependencies between tsetse males and their symbionts at the levels of gene expression, protein synthesis and metabolite production/abundance could be leveraged to develop new ways to generate sterile males. Application of this knowledge to development of targeted chemical based male sterilization strategies could improve sterile male rearing, viability and competitiveness in the field.

\section{Methods}

\section{Insects and sample preparation}

In this work, we used male insects from the G. morsitans colony $\left(\mathrm{Gmm}^{\mathrm{WT}}\right)$ maintained at the Yale University insectary under standard laboratory conditions [96]. Aposymbiotic flies were derived as previously described [12].
Briefly, Gmm ${ }^{\mathrm{WT}}$ females were fed every $48 \mathrm{~h}$ using an artificial feeding system on blood meals supplemented with $20 \mu \mathrm{g} / \mathrm{ml}$ of tetracycline and $10 \%(w / v)$ yeast extract (Becton Dickinson). Dietary supplementation with yeast extract rescues female fecundity facilitating the production of aposymbiotic offspring [12]. Blood feeding continued for the duration of their entire life span. The resulting progeny were confirmed to be aposymbiotic by PCR assays using as template genomic DNA samples from pooled male and female adult flies. DNA was extracted from the whole body of either two or eight day-old adults using the Qiagen DNeasy ${ }^{R}$ Blood \& Tissue kit. Bacterium-specific PCR amplification was achieved using the following primer sets: Wigglesworthia thiC (F-5'-TGAAAACAT TTGCAAAATTTG-3'; R-5'-GGTGTTACATAGCATAA AT-3'; amplicon size 365 bp); Sodalis SscA (F-5'ATTA AAGCGGCAGGTCATCACG-3'; R-5'-ATCGGCGGAG AACATCGGTAAG-3'; amplicon size 400 bp); Wolbachia GroEL (F-5'-GGTGAGCAGTTGCAAGAAGC-3'; R-5'-A GATCTTCCATCTTGATTCC-3'; amplicon size 795 bp). As a control, primers specific to tsetse beta-1 tubulin were used (F-5'-TCGTTGACCATGTCTGGTGT-3'; R-5'-TAG TTCTCTTCAACTTCAGCCTCTT-3'; amplicon size $650 \mathrm{bp})$. PCR reactions were performed using an MJ-Research thermocycler using the following thermal profile: $94^{\circ} \mathrm{C} 45 \mathrm{~s}, 60^{\circ} \mathrm{C} 45 \mathrm{~s}, 72^{\circ} \mathrm{C} 80 \mathrm{~s}$, for 35 cycles. The amplicons were visualized by electrophoresis on a $1 \%$ agarose gel. The male $\mathrm{Gmm}^{\text {Apo }}$ progeny flies were collected at eclosion and divided into biological replicates of 10 flies in parallel with equivalent replicates of control male flies. The flies were maintained on a normal (unmodified) blood diet. At 7 days post-eclosion, the reproductive tracts (comprising male accessory glands, testes and ejaculatory duct) were dissected from the $\mathrm{Gmm}^{\mathrm{WT}}$ and $\mathrm{Gmm}^{\mathrm{Apo}}$ males and stored in TRIzol ${ }^{\circ}$ reagent (Thermo Fisher Scientific, Waltham, MA). For both normal and aposymbiotic males three biological replicates were included in the analysis [29]. Each replicate represents ten pooled male reproductive tracts.

\section{Library preparation and analysis}

Total RNA from male reproductive tissues was extracted according to the TRIzol ${ }^{\circ}$ reagent manufacturer's instructions. Total RNA was treated with Ambion TURBO DNA-free DNase (Thermo Fisher Scientific, Waltham, MA). RNA quality was evaluated using an Agilent 2100 Bioanalyzer (Agilent Technologies, Santa Clara, CA). Male reproductive tract transcriptome libraries were prepared and sequenced by the Yale University Center of Genome Analysis (YCGA, New Haven, CT) using the TruSeq RNA Library Prep Kit according the standard protocols. Libraries were sequenced (75 bp single-end read) on an Illumina HiSeq 2500 machine. The RNA-seq datasets were analyzed with FastQC and trimmed in 
CLC Genomics Workbench (CLC Bio, Cambridge, MA) to remove ambiguous nucleotides. The trimmed datasets were mapped to G. morsitans transcripts (version 1.5, Vectorbase) [97]. Transcript expression levels were analyzed using CLC Genomics Workbench (CLC bio, Cambridge, MA), using RPKM as a measure of relative gene expression [98]. Genes with RPKM > 50 were considered as being significantly expressed within the library. Analysis of differential expression between the control library and treatments was performed using the EdgeR package in $\mathrm{R}$ (version 3.16.5) using the unique counts data derived from the CLC based mapping data. At the time the study was performed, three replicates were considered adequate to determine differential gene expression. More recent works have emphasized the inclusion of larger replicate numbers. Fortunately, the EdgeR package was designed to account for biological and technical variability through the use of empirical bayes methods to improve reliability of differential expression calls and is designed for use with low numbers of replicates [99]. Recent comparisons of RNA-seq analysis packages revealed edge $R$ is one of the top performing packages for controlling False Positive Rates with lower replicates primarily affecting the number of False Negatives due to the conservative nature of the model [100]. Future studies will be performed utilizing larger replicates to increase the depth of our findings. Transcripts were scored as differentially expressed if they had a $P$-value of $<=0.05$ and an FDR value of $<=0.01$. Principal component analysis (PCA) was performed using the prcomp package (version 3.3.1) in the $\mathrm{R}$ software suite and visualized using the Factominer (version 1.36) and factoextra (version 1.0.4) packages.

\section{Comparative analyses with tissue-specific RNAseq libraries} and spermatophore proteome derived from $\mathrm{Gmm}^{\mathrm{WT}}$ males The identified differentially expressed transcripts were then cross-referenced to previously generated transcriptomes from normal (i.e. with full endosymbiotic fauna) males to assign: i) tissue specificity; ii) transcriptional variations in relation to sexual maturation and mating; and iii) ability to encode for spermatophore proteins. The Sequence Read Archive (SRA) numbers for the individual libraries at NCBI are SRX1254426 (testes post-mating), SRX1254425 (testes mature virgin), SRX1254417 (testes teneral), SRX1254054 (MAG post mating), SRX1251081 (MAG mature virgin), SRX1251080 (MAG teneral). Sex specificity was based on normalized gene expression calculated as the Fragments Per Kilobase of Exon per Million reads mapped (FPKM), analysed using the Baggerley's test [101] and filtered with the False Discovery Rate (FDR) $P$-value correction of 0.0001 , in accordance to our previous work [3]. To assign tissue-specificity, we combined the values for the three replicates corresponding to the testes and the MAG libraries we previously produced (i.e. teneral, 3 days old mature virgin, and mated males), respectively, and derived for each transcript an average expression value for each of the two tissues as we described previously [3]. Briefly, in all comparisons, we considered one gene to be tissue-biased when fold change in one tissue was at least 5 -fold higher in expression than in the other. One gene was considered to be tissue-specifically expressed when fold change in one tissue was at least 5 folds higher in expression than in the other and the number of unique reads in the other tissue was less than 50 .

To assign transcriptional variations in relation to sexual maturation and mating, we individually used the six different libraries derived from MAGs and testes from teneral, mature virgin and mated males, respectively, and derived fold change variations as previously described [3]. Briefly, normalized gene expression calculated as FPKM were analysed using the Kal's Z-test [30] with FDR P-value correction $<0.05$. Fold change ratio between the immature males (MAGs or testes tissues) and mature virgin (MAGs or testes tissues) normalized expression means were derived and we defined a gene as maturation-biased when displaying a fold change ratio $>2$ (i.e. up-regulated in response to maturation) and fold change ratio $<0.5$ (i.e. down-regulated in response to maturation). The intermediate ratios were considered unbiased. The fold change ratios between mature virgin (MAGs or testes) and mated (MAGs or testes) normalized expression means were similarly analyzed and allowed to define mating-responsive genes. The intersections among the four groups (i.e. upor down-regulated in response to maturation and upor down-regulated in response to mating) of MAGor testes-biased genes were visualized by venn diagrams [102].

In addition, we cross-referenced the dataset of 135 symbiont-responsive genes with genes corresponding to the identified 287 spermatophore proteins and determined whether, in $\mathrm{Gmm}^{\mathrm{WT}}$ individuals, they were encoding for transferred seminal fluid proteins [3]. O-glycosylation sites in spermatophore proteins were predicted with the program NetOGlyc [103].

\section{Additional files}

Additional file 1: The effect of tetracycline treatment on the maternal transmission of tsetse endosymbionts. PCR assays on genomic DNA showing that Gmm ${ }^{W T}$ flies were positive for Wigglesworthia (Wig Thic), Sodalis (Sod SsaC) and Wolbachia (Wol GroEL), whereas offspring resulting from tetracycline-treated flies lack all three symbionts. The bottom panel shows the amplification of tsetse tubulin beta-1 gene on all samples. A and B lanes represent two PCR replicates performed on pooled genomic DNA from ten males and ten females extracted either at 2 and 8 days post-emergence. (PDF $1070 \mathrm{~kb}$ )

Additional file 2: Principal Component Analysis of gene expression in $\mathrm{Gmm}^{\mathrm{WT}}$ and $\mathrm{Gmm}^{\text {Apo }}$ male reproductive tissues. (PDF $98 \mathrm{~kb}$ ) 
Additional file 3: Excel spreadsheet containing the descriptions of the differentially expressed genes in the reproductive tract tissues between $\mathrm{Gmm}^{\mathrm{WT}}$ and $\mathrm{Gmm}^{\mathrm{Apo}}$ males. (XLSX $67 \mathrm{~kb}$ )

Additional file 4: Gene Ontology analysis of genes down-regulated in $\mathrm{Gmm}^{\mathrm{ApO}}$ male reproductive tissues. The number of genes associated with corresponding Gene Ontology terms (Biological Process, Molecular Function, and Cellular Component Level III) is shown. (PDF $784 \mathrm{~kb}$ )

Additional file 5: Gene Ontology analysis of genes up-regulated in $\mathrm{Gmm}^{\mathrm{ApO}}$ male reproductive tissues. The number of genes associated with corresponding Gene Ontology terms (Biological Process, Molecular Function, and Cellular Component Level III) is shown. (PDF $778 \mathrm{~kb}$ )

Additional file 6: Excel spreadsheet showing the Gene Ontology terms associated to genes down- and up-regulated in $\mathrm{Gmm}^{\mathrm{Apo}}$ male reproductive tissues. (XLSX $54 \mathrm{~kb}$ )

Additional file 7: Changes in transcript abundance in response to maturation and mating in the presence of symbionts of genes downand up-regulated in $\mathrm{Gmm}^{\mathrm{Apo}}$ male reproductive tissues. Fold change difference in expression is separately shown for MAG- and testes-biased genes for A) $\mathrm{Gmm}^{\mathrm{Apo}}$ down-regulated, and B) $\mathrm{Gmm}^{\mathrm{Apo}}$ up-regulated genes. (PDF $893 \mathrm{~kb}$ )

\section{Abbreviations}

Cl: Cytoplasmic Incompatibility; FDR: False Discovery Rate; Gmm ${ }^{\mathrm{Apo}}$ : Aposymbiotic G. morsitans; Gmm WT: Wild-type G. morsitans; GO: Gene Ontology; MAGs: Male Accessory Glands; PCA: Principal Component Analysis; SIT: Sterile Insect Technique

\section{Funding}

This study received support from NIH R21 Al109263-01 "Expanding the toolbox for tsetse reproductive biology" (S.A., G.M.A., A.R.M., F.S.), and the Joint FAO/IAEA Division of Nuclear Techniques in Food and Agriculture, International Atomic Energy Agency, Vienna, Austria (under the Coordinated Research Project No.: D42015) (A.R.M.) within the Coordinated Research Program "Enhancing tsetse fly refractoriness to trypanosome infection". This research is in the frame of the University of Pavia strategic theme "Towards a governance model for international migration: an interdisciplinary and diachronic perspective (MIGRAT-IN-G)." The publication cost of this article was funded by the International Atomic Energy Agency (IAEA) as part of the Coordinated Research Project "Enhancing tsetse fly refractoriness to trypanosome infection". This research was partially supported also by the Slovak Research and Development Agency under the contract No. APW-15-0604 entitled 'Reduction of fecundity and trypanosomiasis control of tsetse flies by the application of sterile insect techniques and molecular methods'.

\section{Availability of data and materials}

The RNAseq libraries generated from the reproductive tract of normal and aposymbiotic males are available in NCBI under the Sequence Read Archive numbers SAMN07362303, SAMN07362304, SAMN07362305, SAMN07362306, SAMN07362307, and SAMN07362308 (control 1, 2 and 3, and aposymbiotic 1,2 , and 3, respectively).

\section{About this supplement}

This article has been published as part of BMC Microbiology Volume 18 Supplement 1, 2018: Enhancing Vector Refractoriness to Trypanosome Infection. The full contents of the supplement are available online at https:// bmcmicrobiol.biomedcentral.com/articles/supplements/volume-18supplement-1.

\section{Authors' contributions}

Conceived and designed the experiments: FS, GMA, SA, and ARM Performed the experiments: FS, GMA, EA, BW, and GS Analyzed the data: FS, GMA, SA, ARM Contributed materials: A-AA, AGP, and PT Wrote the paper: FS, GMA, $S A$, and ARM. All authors read and approved the final manuscript.

\section{Ethics approval and consent to participate}

Not applicable.

\section{Consent for publication}

Not applicable.

\section{Competing interests}

The authors declare that they have no competing interests.

\section{Publisher's Note}

Springer Nature remains neutral with regard to jurisdictional claims in published maps and institutional affiliations.

\section{Author details}

'Department of Biology and Biotechnology, University of Pavia, 27100 Pavia, Italy. ${ }^{2}$ Yale School of Public Health, Department of Epidemiology of Microbial Diseases, New Haven, CT 06520, USA. ${ }^{3}$ Present Address: Department of Entomology and Nematology, University of California Davis, Davis, CA 95616, USA. ${ }^{4}$ Section of Molecular and Applied Zoology, Institute of Zoology, Slovak Academy of Sciences, 84506 Bratislava, SR, Slovakia. International Atomic Energy Agency, Joint FAO/IAEA Division of Nuclear Techniques in Food and Agriculture, IPC Laboratory, A-1400 Vienna, Austria.

\section{Published: 23 November 2018}

\section{References}

1. Benoit JB, Attardo GM, Baumann AA, Michalkova V, Aksoy S. Adenotrophic viviparity in tsetse flies: potential for population control and as an insect model for lactation. Annu Rev Entomol. 2015;60:351-71. https://doi.org/10. 1146/annurev-ento-010814-020834

2. Pollock JN. Male accessory secretions, their use and replenishment in Glossina. Bull Entomol Res. 1974;64:533-9. https://doi.org/10.1017/ S0007485300035847.

3. Scolari F, Benoit JB, Michalkova V, Aksoy E, Takac P, Abd-Alla AMM, et al. The spermatophore in Glossina morsitans morsitans: insights into male contributions to reproduction. Sci Rep. 2016;6:20334. https://doi.org/10. 1038/srep20334.

4. Bing X, Attardo GM, Vigneron A, Aksoy E, Scolari F, Malacrida A, Weiss BL, Aksoy S. Unravelling the relationship between the tsetse fly and its obligate symbiont Wigglesworthia: transcriptomic and metabolomic landscapes reveal highly integrated physiological networks. Proc Biol Sci. 2017; 284(1857):20170360

5. Douglas AE. Multiorganismal insects: diversity and function of resident microorganisms. Annu Rev Entomol. 2015;60:17-34. https://doi.org/10.1146/ annurev-ento-010814-020822.

6. Wang J, Weiss BL, Aksoy S. Tsetse fly microbiota: form and function. Front Cell Infect Microbiol. 2013;3:69. https://doi.org/10.3389/fcimb.2013.00069.

7. Michalkova V, Benoit JB, Weiss BL, Attardo GM, Aksoy S. Vitamin B6 generated by obligate symbionts is critical for maintaining proline homeostasis and fecundity in tsetse flies. Appl Environ Microbiol. 2014; 80(18):5844-53. https://doi.org/10.1128/AEM.01150-14.

8. Attardo GM, Lohs C, Heddi A, Alam UH, Yildirim S, Aksoy S. Analysis of milk gland structure and function in Glossina morsitans: milk protein production, symbiont populations and fecundity. J Insect Physiol. 2008;54(8):1236-42. https://doi.org/10.1016/j.jinsphys.2008.06.008.

9. De Vooght L, Caljon G, Van Hees J, Van Den Abbeele J. Paternal transmission of a secondary symbiont during mating in the viviparous tsetse fly. Mol Biol Evol. 2015;32(8):1977-80. https://doi.org/10.1093/molbev/msv077.

10. McLean AHC, Ferrari J, Godfray HCJ. Do facultative symbionts affect fitness of pea aphids in the sexual generation? Entomol Exp Appl. 2018;166(1):32-40.

11. Werren JH, Baldo L, Clark ME. Wolbachia: master manipulators of invertebrate biology. Nat Rev Microbiol. 2008;6(10):741-51. https://doi.org/ 10.1038/nrmicro1969.

12. Alam U, Medlock J, Brelsfoard C, Pais R, Lohs C, Balmand S, et al. Wolbachia symbiont infections induce strong cytoplasmic incompatibility in the tsetse fly Glossina morsitans. PLoS Pathog. 2011;7(12):e1002415. https://doi.org/10. 1371/journal.ppat.1002415.

13. Doudoumis V, Tsiamis G, Wamwiri F, Brelsfoard C, Alam U, Aksoy E, et al. Detection and characterization of Wolbachia infections in laboratory and natural populations of different species of tsetse flies (genus Glossina). BMC Microbiol. 2012;12(Suppl 1):S3. https://doi.org/10.1186/1471-2180-12-S1-S3.

14. Ouma JO, Marquez JG, Krafsur ES. Patterns of genetic diversity and differentiation in the tsetse fly Glossina morsitans morsitans Westwood populations in east and southern Africa. Genetica. 2007:130(2):139-51. https://doi.org/10.1007/s10709-006-9001-0.

15. Krafsur ES. Tsetse flies: genetics, evolution, and role as vectors. Infect Genet Evol. 2009;9(1):124-41. 
16. Brelsfoard C, Tsiamis G, Falchetto M, Gomulski LM, Telleria E, Alam U, et al. Presence of extensive Wolbachia symbiont insertions discovered in the genome of its host Glossina morsitans morsitans. PLoS Negl Trop Dis. 2014; 8(4):e2728. https://doi.org/10.1371/journal.pntd.0002728.

17. Iturbe-Ormaetxe I, Burke GR, Riegler M, O'Neill SL. Distribution, expression, and motif variability of ankyrin domain genes in Wolbachia pipientis. J Bacteriol. 2005;187(15):5136-45. https://doi.org/10.1128/JB.187.15.5136-5145.2005.

18. Duron O, Boureux A, Echaubard P, Berthomieu A, Berticat C, Fort P, et al. Variability and expression of ankyrin domain genes in Wolbachia variants infecting the mosquito Culex pipiens. J Bacteriol. 2007;189(12):4442-8. https://doi.org/10.1128/JB.00142-07.

19. Tram U, Sullivan W. Role of delayed nuclear envelope breakdown and mitosis in Wolbachia-induced cytoplasmic incompatibility. Science. 2002; 296(5570):1124-6. https://doi.org/10.1126/science.1070536.

20. Zheng Y, Wang JL, Liu C, Wang CP, Walker T, Wang YF. Differentially expressed profiles in the larval testes of Wolbachia infected and uninfected Drosophila. BMC Genomics. 2011;12:595. https://doi.org/10.1186/1471-2164-12-595.

21. Yuan $L L$, Chen $X$, Zong Q, Zhao T, Wang JL, Zheng Y, et al. Quantitative proteomic analyses of molecular mechanisms associated with cytoplasmic incompatibility in Drosophila melanogaster induced by Wolbachia. J Proteome Res. 2015;14(9):3835-47. https://doi.org/10.1021/acs.jproteome. 5 b00191.

22. Kremer $\mathrm{N}$, Charif $\mathrm{D}$, Henri $\mathrm{H}$, Gavory F, Wincker $\mathrm{P}$, Mavingui $\mathrm{P}$, et al. Influence of Wolbachia on host gene expression in an obligatory symbiosis. BMC Microbiol. 2012;12(Suppl 1):S7. https://doi.org/10.1186/1471-2180-12-S1-S7.

23. Kambris Z, Blagborough AM, Pinto $S B$, Blagrove MS, Godfray HC, Sinden RE, et al. Wolbachia stimulates immune gene expression and inhibits plasmodium development in Anopheles gambiae. PLoS Pathog. 2010;6(10): e1001143. https://doi.org/10.1371/journal.ppat.1001143.

24. Mayoral JG, Hussain M, Joubert DA, Iturbe-Ormaetxe I, O'Neill SL, Asgari S. Wolbachia small noncoding RNAs and their role in cross-kingdom communications. Proc Natl Acad Sci U S A. 2014;111(52):18721-6. https:// doi.org/10.1073/pnas.1420131112

25. Hussain M, Frentiu FD, Moreira LA, O'Neill SL, Asgari S. Wolbachia uses host microRNAs to manipulate host gene expression and facilitate colonization of the dengue vector Aedes aegypti. Proc Natl Acad Sci U S A. 2011;108(22): 9250-5. https://doi.org/10.1073/pnas.1105469108.

26. Shropshire JD, Bordenstein SR. Speciation by symbiosis: the microbiome and behavior. MBio. 2016;7(2):e01785. https://doi.org/10.1128/mBio.01785-15.

27. Morimoto J, Wigby S. Differential effects of male nutrient balance on pre- and post-copulatory traits, and consequences for female reproduction in Drosophila melanogaster. Sci Rep. 2016;6:27673. https://doi.org/10.1038/srep27673.

28. Pais R, Lohs C, Wu YN, Wang JW, Aksoy S. The obligate mutualist Wigglesworthia glossinidia influences reproduction, digestion, and immunity processes of its host, the tsetse fly. Appl Environ Microbiol. 2008;74(19):5965-74.

29. Conesa A, Madrigal P, Tarazona S, Gomez-Cabrero D, Cervera A, McPherson A, et al. A survey of best practices for RNA-seq data analysis. Genome Biol. 2016;17:13. https://doi.org/10.1186/s13059-016-0881-8.

30. Kal AJ, van Zonneveld AJ, Benes V, van den Berg M, Koerkamp MG, Albermann $\mathrm{K}$, et al. Dynamics of gene expression revealed by comparison of serial analysis of gene expression transcript profiles from yeast grown on two different carbon sources. Mol Biol Cell. 1999;10(6):1859-72.

31. Benoit JB, Vigneron A, Broderick NA, Wu Y, Sun JS, Carlson JR, Aksoy S, Weiss BL. Symbiont-induced odorant binding proteins mediate insect host hematopoiesis. Elife. 2017;6. https://doi.org/10.7554/eLife.19535.

32. Fehlbaum $P$, Bulet $P$, Chernysh $S$, Briand JP, Roussel JP, Letellier $L$, et al. Structure-activity analysis of thanatin, a 21-residue inducible insect defense peptide with sequence homology to frog skin antimicrobial peptides. Proc Natl Acad Sci U S A. 1996;93(3):1221-5. https://doi.org/ 10.1073/pnas.93.3.1221.

33. Findlay GD, Yi X, Maccoss MJ, Swanson WJ. Proteomics reveals novel Drosophila seminal fluid proteins transferred at mating. PLoS Biol. 2008;6(7): e178. https://doi.org/10.1371/journal.pbio.0060178.

34. Kelleher ES, Watts TD, LaFlamme BA, Haynes PA, Markow TA. Proteomic analysis of Drosophila mojavensis male accessory glands suggests novel classes of seminal fluid proteins. Insect Biochem Mol Biol. 2009;39(5-6):36671. https://doi.org/10.1016/j.ibmb.2009.03.003.

35. Sirot LK, Hardstone MC, Helinski ME, Ribeiro JM, Kimura M, Deewatthanawong $P$, et al. Towards a semen proteome of the dengue vector mosquito: protein identification and potential functions. PLoS Negl Trop Dis. 2011;5(3):e989. https://doi.org/10.1371/journal.pntd.0000989.
36. Dottorini T, Persampieri T, Palladino P, Baker DA, Spaccapelo R, Senin N, et al. Regulation of Anopheles gambiae male accessory gland genes influences postmating response in female. FASEB J. 2013;27(1):86-97. https://doi.org/ 10.1096/fj.12-219444

37. Wei $D$, Li HM, Tian CB, Smagghe G, Jia FX, Jiang HB, et al. Proteome analysis of male accessory gland secretions in oriental fruit flies reveals juvenile hormone-binding protein, suggesting impact on female reproduction. Sci Rep. 2015;5:16845. https://doi.org/10.1038/srep16845.

38. Peng Y, Grassl J, Millar AH, Baer B. Seminal fluid of honeybees contains multiple mechanisms to combat infections of the sexually transmitted pathogen Nosema apis. Proc Biol Sci. 2016;283(1823):20151785.

39. Gramates LS, Marygold SJ, dos Santos G, Urbano JM, Antonazzo G, Matthews BB, et al. FlyBase at 25: looking to the future. Nucleic Acids Res. 2017;45(D1):D663-D71. https://doi.org/10.1093/nar/gkw1016.

40. Sitnik UL, Gligorov D, Maeda RK, Karch F, Wolfner MF. The female postmating response requires genes expressed in the secondary cells of the male accessory gland in Drosophila melanogaster. Genetics. 2016;202(3): 1029-41. https://doi.org/10.1534/genetics.115.181644.

41. Gillott C, Langley PA. The control of receptivity and ovulation in the tsetse fly, Glossina morsitans. Physiol Entomol. 1981;6(3):269-81.

42. Yang G, Attardo GM, Lohs C, Aksoy S. Molecular characterization of two novel milk proteins in the tsetse fly (Glossina morsitans morsitans). Insect Mol Biol. 2010;19(2):253-62. https://doi.org/10.1111/j.1365-2583.2009.00987.x.

43. Sterkel M, Perdomo HD, Guizzo MG, Barletta ABF, Nunes RD, Dias FA, et al. Tyrosine detoxification is an essential trait in the life history of bloodfeeding arthropods. Curr Biol. 2016;26(16):2188-93. https://doi.org/10.1016/j. cub.2016.06.025.

44. Sterkel M, Oliveira JHM, Bottino-Rojas V, Paiva-Silva GO, Oliveira PL. The dose makes the poison: nutritional overload determines the life traits of bloodfeeding arthropods. Trends Parasitol. 2017;33(8):633-44. https://doi.org/10. 1016/j.pt.2017.04.008.

45. Fuchs S, Behrends V, Bundy JG, Crisanti A, Nolan T. Phenylalanine metabolism regulates reproduction and parasite melanization in the malaria mosquito. PLoS One. 2014;9(1):e84865. https://doi.org/10.1371/journal.pone.0084865.

46. Akman L, Yamashita A, Watanabe H, Oshima K, Shiba T, Hattori M, et al. Genome sequence of the endocellular obligate symbiont of tsetse flies, Wigglesworthia glossinidia. Nat Genet. 2002;32(3):402-7. https://doi.org/10.1038/ng986.

47. Lee GH, Bahn JH, Park JH. Sex- and clock-controlled expression of the neuropeptide F gene in Drosophila. Proc Natl Acad Sci U S A. 2006;103(33): 12580-5. https://doi.org/10.1073/pnas.0601171103.

48. Van Wielendaele P, Wynant N, Dillen S, Zels S, Badisco L, Vanden Broeck J. Neuropeptide $\mathrm{F}$ regulates male reproductive processes in the desert locust, Schistocerca gregaria. Insect Biochem Mol Biol. 2013;43(3):252-9. https://doi. org/10.1016/j.ibmb.2012.12.004.

49. Bartholome O, Van den Ackerveken P, Sanchez Gil J, de la Brassinne Bonardeaux O, Leprince P, Franzen R, et al. Puzzling out synaptic vesicle 2 family members functions. Front Mol Neurosci. 2017;10:148. https://doi.org/ 10.3389/fnmol.2017.00148.

50. Janz R, Hofmann K, Sudhof TC. SVOP, an evolutionarily conserved synaptic vesicle protein, suggests novel transport functions of synaptic vesicles. Neurosci. 1998;18(22):9269-81.

51. Morozova TV, Anholt RRH, Mackay TFC. Transcriptional response to alcohol exposure in Drosophila melanogaster. Genome Biol. 2006;7(10):R95. https:// doi.org/10.1186/gb-2006-7-10-r95.

52. Fiumera AC, Dumont BL, Clark AG. Associations between sperm competition and natural variation in male reproductive genes on the third chromosome of Drosophila melanogaster. Genetics. 2007;176(2):1245-60. https://doi.org/10.1534/genetics.106.064915.

53. Mueller JL, Linklater JR, Ram KR, Chapman T, Wolfner MR. Targeted gene deletion and phenotypic analysis of the Drosophila melanogaster seminal fluid protease inhibitor Acp62F. Genetics. 2008;178(3):1605-14. https://doi. org/10.1534/genetics.107.083766.

54. Laflamme BA, Wolfner MF. Identification and function of proteolysis regulators in seminal fluid. Mol Reprod Dev. 2013;80(2):80-101. https://doi. org/10.1002/mrd.22130.

55. Otti O, Naylor RA, Siva-Jothy MT, Reinhardt K. Bacteriolytic activity in the ejaculate of an insect. Am Nat. 2009;174(2):292-5. https://doi.org/10.1086/ 600099.

56. Samakovlis C, Kylsten P, Kimbrell DA, Engstrom A, Hultmark D. The andropin gene and its product, a male-specific antibacterial peptide in Drosophila melanogaster. EMBO J. 1991;10(1):163-9. 
57. Mueller $J$, Page $J$, Wolfner MF. An ectopic expression screen reveals the protective and toxic effects of Drosophila seminal fluid proteins. Genetics. 2007;175(2):777-83. https://doi.org/10.1534/genetics.106.065318.

58. Wolfner MF. Battle and ballet: molecular interactions between the sexes in Drosophila. J Hered. 2009;100(4):399-410.

59. Rogers DW, Whitten MMA, Thailayil J, Soichot J, Levashina EA, Catteruccia F. Molecular and cellular components of the mating machinery in Anopheles gambiae females. Proc Natl Acad Sci U S A. 2008;105(49):19390-5. https:// doi.org/10.1073/pnas.0809723105

60. Sirot LK, Poulson RL, McKenna MC, Girnary H, Wolfner MF, Harrington LC. Identity and transfer of male reproductive gland proteins of the dengue vector mosquito, Aedes aegypti: potential tools for control of female feeding and reproduction. Insect Biochem Mol Biol. 2008;38(2):176-89.

61. Chapman T, Davies SJ. Functions and analysis of the seminal fluid proteins of male Drosophila melanogaster fruit flies. Peptides. 2004;25(9):1477-90. https://doi.org/10.1016/j.peptides.2003.10.023.

62. Avila FW, Sirot LK, LaFlamme BA, Rubinstein CD, Wolfner MF. Insect seminal fluid proteins: identification and function. Annu Rev Entomol. 2011;56:21-40. https://doi.org/10.1146/annurev-ento-120709-144823.

63. Lung $\mathrm{O}$, Kuo L, Wolfner MF. Drosophila males transfer antibacterial proteins from their accessory gland and ejaculatory duct to their mates. J Insect Physiol. 2001;47(6):617-22.

64. Kraaijeveld AR, Wertheim B. Costs and genomic aspects of Drosophila immunity to parasites and pathogens. In: Rolff J, Reynolds S, editors. Insect infection and immunity: evolution, ecology, and mechanisms. Oxford biology. Oxford: Oxford University Press; 2009. p. 254.

65. De Gregorio E, Spellman PT, Rubin GM, Lemaitre B. Genome-wide analysis of the Drosophila immune response by using oligonucleotide microarrays. Proc Natl Acad Sci U S A. 2001;98(22):12590-5. https://doi.org/10.1073/pnas.221458698.

66. Schlenke TA, Morales J, Govind S, Clark AG. Contrasting infection strategies in generalist and specialist wasp parasitoids of Drosophila melanogaster. PLoS Pathog. 2007;3(10):1486-501. https://doi.org/10.1371/journal.ppat.0030158.

67. Ranasinghe S, McManus DP. Structure and function of invertebrate Kunitz serine protease inhibitors. Dev Comp Immunol. 2013;39(3):219-27. https:// doi.org/10.1016/j.dci.2012.10.005.

68. Ellisdon AM, Zhang Q, Henstridge MA, Johnson TK, Warr CG, Law RH, et al. High resolution structure of cleaved serpin 42 Da from Drosophila melanogaster. BMC Struct Biol. 2014;14:14. https://doi.org/10.1186/14726807-14-14.

69. Bruning M, Lummer M, Bentele C, Smolenaars MM, Rodenburg KW, Ragg H. The Spn4 gene from Drosophila melanogaster is a multipurpose defence tool directed against proteases from three different peptidase families. Biochem J. 2007:401(1):325-31. https://doi.org/10.1042/BJ20060648.

70. Hamilton PT, Leong JS, Koop BF, Perlman SJ. Transcriptional responses in a Drosophila defensive symbiosis. Mol Ecol. 2014;23(6):1558-70. https://doi. org/10.1111/mec.12603.

71. Lemaitre B, Hoffmann J. The host defense of Drosophila melanogaster. Annu Rev Immunol. 2007;25:697-743. https://doi.org/10.1146/annurev.immunol.25. 022106.141615 .

72. Tran DT, Ten Hagen KG. Mucin-type O-glycosylation during development. J Biol Chem. 2013;288(10):6921-9. https://doi.org/10.1074/jbc.R112.418558.

73. Kaji K, Oda S, Shikano T, Ohnuki T, Uematsu Y, Sakagami J, et al. The gamete fusion process is defective in eggs of Cd9-deficient mice. Nat Genet. 2000; 24(3):279-82.

74. Miyado K, Yamada G, Yamada S, Hasuwa H, Nakamura Y, Ryu F, et al. Requirement of CD9 on the egg plasma membrane for fertilization. Science. 2000;287(5451):321-4.

75. Le Naour F, Rubinstein E, Jasmin C, Prenant M, Boucheix C. Severely reduced female fertility in CD9-deficient mice. Science. 2000;287(5451):319-21.

76. Boes KE, Ribeiro JM, Wong A, Harrington LC, Wolfner MF, Sirot LK. Identification and characterization of seminal fluid proteins in the Asian tiger mosquito, Aedes albopictus. PLoS Negl Trop Dis. 2014;8(6): e2946.

77. Hurst D, Rylett CM, Isaac RE, Shirras AD. The Drosophila angiotensinconverting enzyme homologue Ance is required for spermiogenesis. Dev Biol. 2003;254(2):238-47. https://doi.org/10.1016/S0012-1606(02)00082-9.

78. Xi Z, Gavotte L, Xie Y, Dobson SL. Genome-wide analysis of the interaction between the endosymbiotic bacterium Wolbachia and its Drosophila host. BMC Genomics. 2008;9:1. https://doi.org/10.1186/1471-2164-9-1.

79. Hughes GL, Ren X, Ramirez JL, Sakamoto JM, Bailey JA, Jedlicka AE, et al. Wolbachia infections in Anopheles gambiae cells: transcriptomic characterization of a novel host-symbiont interaction. PLoS Pathog. 2011; 7(2):e1001296. https://doi.org/10.1371/journal.ppat.1001296.

80. Almeida CG, Yamada A, Tenza D, Louvard D, Raposo G, Coudrier E. Myosin $1 \mathrm{~b}$ promotes the formation of post-Golgi carriers by regulating actin assembly and membrane remodelling at the trans-Golgi network. Nat Cell Biol. 2011;13(7):779-89. https://doi.org/10.1038/ncb2262.

81. Serano J, Rubin GM. The Drosophila synaptotagmin-like protein bitesize is required for growth and has $\mathrm{mRNA}$ localization sequences within its open reading frame. Proc Natl Acad Sci U S A. 2003;100(23):13368-73. https://doi. org/10.1073/pnas.1835727100.

82. Pilot F, Philippe JM, Lemmers C, Lecuit T. Spatial control of actin organization at adherens junctions by a synaptotagmin-like protein Btsz. Nature. 2006:442(7102):580-4. https://doi.org/10.1038/nature04935.

83. Kaltschmidt B, Glatzer KH, Michiels F, Leiss D, Renkawitz-Pohl R. During Drosophila spermatogenesis beta 1 , beta 2 and beta 3 tubulin isotypes are cell-type specifically expressed but have the potential to coassemble into the axoneme of transgenic flies. Eur J Cell Biol. 1991;54(1):110-20.

84. Kimble M, Dettman RW, Raff EC. The beta 3-tubulin gene of Drosophila melanogaster is essential for viability and fertility. Genetics. 1990;126(4):991-1005.

85. Holembowski L, Kramer D, Riedel D, Sordella R, Nemajerova A, Dobbelstein $M$, et al. TAp73 is essential for germ cell adhesion and maturation in testis. J Cell Biol. 2014;204(7):1173-90. https://doi.org/10.1083/jcb.201306066.

86. Tanentzapf G, Devenport D, Godt D, Brown NH. Integrin-dependent anchoring of a stem-cell niche. Nat Cell Biol. 2007;9(12):1413-U127. https:// doi.org/10.1038/ncb1660.

87. Wasbrough ER, Dorus S, Hester S, Howard-Murkin J, Lilley K, Wilkin E, et al. The Drosophila melanogaster sperm proteome-II (DmSP-II). J Proteome. 2010;73(11):2171-85. https://doi.org/10.1016/j.jprot.2010.09.002.

88. Prayer-Galetti T, Rossi GP, Belloni AS, Albertin G, Battanello W, Piovan $V_{\text {, et }}$ al. Gene expression and autoradiographic localization of endothelin-1 and its receptors $\mathrm{a}$ and $\mathrm{B}$ in the different zones of the normal human prostate. J Urol. 1997:157(6):2334-9.

89. Telemaque S, D'Orleans-Juste P. Presence of a phosphoramidon-sensitive endothelin-converting enzyme which converts big-endothelin-1, but not big-endothelin-3, in the rat vas deferens. Naunyn Schmiedeberg's Arch Pharmacol. 1991;344(4):505-7.

90. Korth P, Bohle RM, Corvol P, Pinet F. Cellular distribution of endothelinconverting enzyme-1 in human tissues. J Histochem Cytochem. 1999:47(4): 447-62. https://doi.org/10.1177/002215549904700403.

91. Casey ML, Byrd W, MacDonald PC. Massive amounts of immunoreactive endothelin in human seminal fluid. J Clin Endocrinol Metab. 1992;74(1):2235. https://doi.org/10.1210/jcem.74.1.1727824.

92. Hammami MM, Haq A, AlSedairy S. The level of endothelin-like immunoreactivity in seminal fluid correlates positively with semen volume and negatively with plasma gonadotrophin levels. Clin Endocrinol. 1994; 40(3):361-6.

93. Bonilla $\mathrm{E}, \mathrm{Xu} \mathrm{EY}$. Identification and characterization of novel mammalian spermatogenic genes conserved from fly to human. Mol Hum Reprod. 2008; 14(3):137-42. https://doi.org/10.1093/molehr/gan002.

94. White-Cooper H, Doggett K, Ellis R. The evolution of spermatogenesis. In: Birkhead TR, Hosken DJ, Pitnick SS, editors. Sperm biology: an evolutionary perspective. New York: Academic Press; 2009. p. 151-83.

95. Ravi Ram K, Wolfner MF. Sustained post-mating response in Drosophila melanogaster requires multiple seminal fluid proteins. PLoS Genet. 2007;3: e238. https://doi.org/10.1371/journal.pgen.0030238.

96. Aksoy S. Establishment and maintenance of small scale tsetse colonies. In: Maramorosch K, Mahmood F, editors. Maintenance of Human, Animal and Plant Pathogen Vectors. New Hampshire: Science Publishers, Inc; 1999. p. 123-36.

97. Lawson D, Arensburger P, Atkinson P, Besansky NJ, Bruggner RV, Butler R, et al. VectorBase: a home for invertebrate vectors of human pathogens. Nucleic Acids Res. 2007;35(suppl 1):D503-D5. https://doi.org/10.1093/nar/gkl960.

98. Mortazavi A, Williams BA, McCue K, Schaeffer L, Wold B. Mapping and quantifying mammalian transcriptomes by RNA-Seq. Nat Methods. 2008;5(7): 621-8. https://doi.org/10.1038/nmeth.1226.

99. Robinson MD, McCarthy DJ, Smyth GK. edgeR: a Bioconductor package for differential expression analysis of digital gene expression data. Bioinformatics. 2010;26(1):139-40. https://doi.org/10.1093/bioinformatics/btp616.

100. Schurch NJ, Schofield P, Gierlinski M, Cole C, Sherstnev A, Singh V, et al. How many biological replicates are needed in an RNA-seq experiment and which differential expression tool should you use? RNA. 2016;22(6):839-51. https://doi.org/10.1261/rna.053959.115. 
101. Baggerley K, Deng L, Morris J, Aldaz C. Differential expression in SAGE: accounting for normal between-library variation. Bioinformatics (Oxf). 2003; 19:1477-83.

102. Bioinformatics \& Evolutionary Genomics. http://bioinformatics.psb.ugent.be/ webtools/Nenn/. Accessed 18 July 2017.

103. Steentoft C, Vakhrushev SY, Joshi HJ, Kong Y, Vester-Christensen MB, Schjoldager KT, et al. Precision mapping of the human O-GaINAC glycoproteome through SimpleCell technology. EMBO J. 2013;32(10):147888. https://doi.org/10.1038/emboj.2013.79.

Ready to submit your research? Choose BMC and benefit from:

- fast, convenient online submission

- thorough peer review by experienced researchers in your field

- rapid publication on acceptance

- support for research data, including large and complex data types

- gold Open Access which fosters wider collaboration and increased citations

- maximum visibility for your research: over $100 \mathrm{M}$ website views per year

At BMC, research is always in progress.

Learn more biomedcentral.com/submissions 